LA WAE NCE LWEAMCAE NATIONAL LABOAATOPY

\title{
Final Report for LDRD Project 06-ERD-063
}

H. R. Beller, A. Chakicherla, M. A. Coleman, B. K. Esser, S. R. Kane, T. C. Legler, T. E. Letain

February 2008 


\section{Disclaimer}

This document was prepared as an account of work sponsored by an agency of the United States Government. Neither the United States Government nor Lawrence Livermore National Security, LLC, nor any of their employees, makes any warranty, express or implied, or assumes any legal liability or responsibility for the accuracy, completeness, or usefulness of any information, apparatus, product, or process disclosed, or represents that its use would not infringe privately owned rights. Reference herein to any specific commercial product, process, or service by trade name, trademark, manufacturer, or otherwise, does not necessarily constitute or imply its endorsement, recommendation, or favoring by the United States Government or Lawrence Livermore National Security, LLC. The views and opinions of authors expressed herein do not necessarily state or reflect those of the United States Government or Lawrence Livermore National Security, LLC, and shall not be used for advertising or product endorsement purposes.

\section{Auspices Statement}

This work was performed under the auspices of the U. S. Department of Energy by Lawrence Livermore National Laboratory under Contract DE-AC52-07NA27344. This work was funded by the Laboratory Directed Research and Development Program at LLNL under project tracking code 06-ERD-063. 


\section{FY07 LDRD Final Report LDRD Project Tracking Code: 06-ERD-063 Harry R. Beller, Principal Investigator}

\section{PROJECT DESCRIPTION}

Using the widespread chemolithoautotrophic bacterium Thiobacillus denitrificans as a model organism, this project integrated genome-enabled techniques to explore novel metabolic (oxidation-reduction) pathways and bacteria-mineral interactions that could mediate the behavior of uranium in aquifers. This is particularly pertinent to a groundwater remediation process that is of great interest to the U.S Department of Energy: in situ, reductive immobilization of metals, including radionuclides. In previous studies, we performed a detailed analysis of the genome of T. denitrificans (including manual curation and comparative genomics) and conducted physiological studies of the anaerobic, nitrate-dependent oxidation of U(IV)-containing minerals by $T$. denitrificans. This 1.5 -year project built on those previous studies and entailed wholegenome transcriptional analysis with high-density, oligonucleotide microarrays as well as development of a genetic system for $T$. denitrificans, with which targeted genes could be disrupted ("knocked out") and complemented in trans.

\section{RESEARCH ACTIVITIES AND TECHNICAL OUTCOME}

\section{OVERVIEW}

The activities and technical outcomes of studies undertaken for this 1.5-year LDRD project are described in the two associated journal articles included in this final report:

- $\quad$ Beller, H. R., T. E. Letain, A. Chakicherla, S. R. Kane, T. C. Legler, and M. A. Coleman. 2006. Whole-genome transcriptional analysis of chemolithoautotrophic thiosulfate oxidation by Thiobacillus denitrificans under aerobic vs. denitrifying conditions. Journal of Bacteriology 188:7005-7015. [UCRL-JRNL-220798]

- Letain, T. E., S. R. Kane, T. C. Legler, E. P. Salazar, P. G. Agron, and H. R. Beller. 2007. Development of a genetic system for the chemolithoautotrophic bacterium Thiobacillus denitrificans. Applied and Environmental Microbiology 73:3265-3271. [UCRL-JRNL-226908] 


\section{MAJOR ACCOMPLISHMENTS}

- We completed and analyzed whole-genome cDNA microarray (transcriptome profiling) experiments with $T$. denitrificans cells induced under aerobic versus denitrifying conditions (the latter conditions are relevant to nitrate-dependent U(IV) oxidation); these studies revealed many novel aspects of how key metabolic genes in this facultative bacterium are modulated in response to changes in the terminal electron acceptor (Beller et al. 2006).

- We successfully developed a genetic system for T. denitrificans and demonstrated its effectiveness by targeting a gene encoding a large subunit of a [NiFe]hydrogenase (Letain et al. 2007); hydrogenases are environmentally relevant in $T$. denitrificans, as we previously showed that nitrate-dependent U(IV) oxidation in this bacterium is dependent on $\mathrm{H}_{2}$ oxidation. We demonstrated not only that we could successfully disrupt a targeted gene, but also that we could complement the mutant with an expression vector that we engineered and could also generate double mutants. This genetic system will be an invaluable tool for future studies of nitrate-dependent U(IV) oxidation and other metabolic processes in $T$. denitrificans.

- The PI (Beller) was invited to present some of this work at the $106^{\text {th }}$ General Meeting of the American Society for Microbiology (Orlando, FL) in a presentation entitled "Genomic and transcriptomic insights into the metabolism of the obligate chemolithoautotroph Thiobacillus denitrificans." [UCRL-PRES-219902].

- We presented a poster at the $107^{\text {th }}$ General Meeting of the American Society for Microbiology (Toronto, Canada) entitled "Development of a genetic system for the U(IV)-oxidizing bacterium Thiobacillus denitrificans." [UCRL-ABS-229989]. 
LA WAENCE LIWEAMCAE WATIONAL LABOAATOAY

Whole-Genome Transcriptional Analysis of Chemolithoautotrophic Thiosulfate Oxidation by Thiobacillus denitrificans Under Aerobic vs. Denitrifying Conditions

H. R. Beller, T. E. Letain, A. Chakicherla, S. R. Kane, T. C. Legler, and M. A. Coleman

Published October 2006

Published in the Journal of Bacteriology 


\title{
Whole-Genome Transcriptional Analysis of Chemolithoautotrophic Thiosulfate Oxidation by Thiobacillus denitrificans under Aerobic versus Denitrifying Conditions $†$
}

\author{
Harry R. Beller, ${ }^{*}$ Tracy E. Letain, Anu Chakicherla, Staci R. Kane, \\ Tina C. Legler, and Matthew A. Coleman \\ Lawrence Livermore National Laboratory, Livermore, California 94551
}

Received 21 April 2006/Accepted 18 July 2006

\begin{abstract}
Thiobacillus denitrificans is one of the few known obligate chemolithoautotrophic bacteria capable of energetically coupling thiosulfate oxidation to denitrification as well as aerobic respiration. As very little is known about the differential expression of genes associated with key chemolithoautotrophic functions (such as sulfur compound oxidation and $\mathrm{CO}_{2}$ fixation) under aerobic versus denitrifying conditions, we conducted wholegenome, cDNA microarray studies to explore this topic systematically. The microarrays identified 277 genes (approximately $10 \%$ of the genome) as differentially expressed using RMA (robust multiarray average) statistical analysis and a twofold cutoff. Genes upregulated (ca. 6- to 150-fold) under aerobic conditions included a cluster of genes associated with iron acquisition (e.g., siderophore-related genes), a cluster of cytochrome $c b b_{3}$ oxidase genes, $c b b L$ and $c b b S$ (encoding the large and small subunits of form I ribulose 1,5-bisphosphate carboxylase/oxygenase, or RubisCO), and multiple molecular chaperone genes. Genes upregulated (ca. 4- to 95-fold) under denitrifying conditions included nar, nir, and nor genes (associated, respectively, with nitrate reductase, nitrite reductase, and nitric oxide reductase, which catalyze successive steps of denitrification), $c b b M$ (encoding form II RubisCO), and genes involved with sulfur compound oxidation (including two physically separated but highly similar copies of sulfide:quinone oxidoreductase and of $d s r C$, associated with dissimilatory sulfite reductase). Among genes associated with denitrification, relative expression levels (i.e., degree of upregulation with nitrate) tended to decrease in the order nar $>$ nir $>$ nor $>$ nos. Reverse transcription-quantitative PCR analysis was used to validate these trends.
\end{abstract}

Thiobacillus denitrificans is an obligately chemolithoautotrophic bacterium characterized by its ability to conserve energy from the oxidation of inorganic sulfur compounds under either aerobic or denitrifying conditions (5). As a facultative anaerobe, $T$. denitrificans may benefit from modulating key components of its energy metabolism, such as sulfur compound oxidation or carbon dioxide fixation, according to whether oxygen or nitrate is the terminal electron acceptor. For example, $T$. denitrificans can express both form I and form II ribulose 1,5-bisphosphate carboxylase/oxygenase (RubisCO), which have different relative affinities for $\mathrm{CO}_{2}$ and the competing substrate $\mathrm{O}_{2}$ and therefore may differ in $\mathrm{CO}_{2}$ fixation efficiency under aerobic versus denitrifying conditions. Also, among its large complement of genes associated with sulfur compound oxidation, $T$. denitrificans shares some genes with aerobic, chemolithotrophic sulfur-oxidizing bacteria and some with anaerobic, phototrophic sulfur bacteria (5). There is very little information on how (or whether) $T$. denitrificans modulates the expression of these sulfur-oxidizing genes as a function of the prevailing terminal electron acceptor. The recent availability of the complete genome sequence of $T$. denitrificans (5) and of high-density oligonucleotide microarrays provided us an opportunity to address

* Corresponding author. Mailing address: Lawrence Livermore National Laboratory, P. O. Box 808, L-542, Livermore, CA 94551-0808. Phone: (925) 422-0081. Fax: (925) 423-7998. E-mail: beller2@1lnl.gov.

$\dagger$ Supplemental material for this article may be found at http://jb .asm.org/. these and other questions by systematically investigating differential expression across the entire $T$. denitrificans genome under aerobic versus denitrifying conditions.

\section{MATERIALS AND METHODS}

Cell growth and exposure conditions. To represent gene expression under denitrifying conditions, $T$. denitrificans (ATCC strain 25259, obtained from the American Type Culture Collection) was cultivated at $30^{\circ} \mathrm{C}$ under strictly anaerobic conditions as described previously (4) with growth medium that contained $20 \mathrm{mM}$ thiosulfate, $20 \mathrm{mM}$ nitrate, and $30 \mathrm{mM}$ bicarbonate $(\mathrm{pH} \sim 7)$. For exposure immediately before harvesting of RNA, 1,200 ml of cells in late exponential phase $\left(1 \times 10^{8}\right.$ to $2 \times 10^{8}$ cells $\left./ \mathrm{ml}\right)$ was harvested anaerobically by centrifugation $\left(13,400 \times g, 15^{\circ} \mathrm{C}, 10 \mathrm{~min}\right)$ and resuspended in modified growth medium (phosphate concentration reduced to $1.5 \mathrm{mM}$ ), and three $10-\mathrm{ml}$ replicates (ca. $7.3 \mathrm{mg}$ protein each) in sealed vials $\left(90 \% \mathrm{~N}_{2}-10 \% \mathrm{CO}_{2}\right.$ headspace) were incubated for ca. $35 \mathrm{~min}$. Cell growth, resuspension, and incubation were performed in an anaerobic glove box (4).

To represent gene expression under aerobic conditions, $T$. denitrificans was cultivated (two successive transfers) with growth medium that differed from the denitrifying medium in several noteworthy respects: it contained no nitrate, it was equilibrated with atmospheric oxygen (rotating in a shake flask at $200 \mathrm{rpm}$ ), and it contained $70 \mathrm{mM}$ phosphate, $0.7 \mu \mathrm{M}$ copper (compared to $1.2 \mu \mathrm{M}$ in denitrifying medium), and $10 \mu \mathrm{M}$ iron (compared to $7.5 \mu \mathrm{M}$ ). The reason for using a higher phosphate buffer concentration in the aerobic medium was that, when lower phosphate concentrations were tested, the $\mathrm{pH}$ of aerobic growth medium dropped from $\sim 7$ to $\sim 5$ as $T$. denitrificans oxidized thiosulfate. This follows from the stoichiometry of thiosulfate oxidation, which yields fivefold more protons per mole of thiosulfate under aerobic than denitrifying conditions. For exposure immediately before harvesting of RNA, 1,200 $\mathrm{ml}$ of cells in late exponential phase was harvested by centrifugation and resuspended in aerobic growth medium, and three 10-ml replicates (ca. $3.9 \mathrm{mg}$ protein each) were incubated at $30^{\circ} \mathrm{C}$ in $125-\mathrm{ml}$ Erlenmeyer flasks rotating at $200 \mathrm{rpm}$ for $60 \mathrm{~min}$. The $\mathrm{pH}$ of the cell suspensions remained in the circumneutral range throughout the incubation period. 
Metabolic activity (thiosulfate oxidation to sulfate, nitrate consumption in anaerobic cultures) was assessed in all anaerobic and aerobic suspensions by sampling each culture twice: immediately upon resuspension and immediately before harvesting for RNA. Ion chromatography was used to determine thiosulfate, sulfate, and nitrate concentrations (4). Previous experiments indicated that metabolic rates during suspensions were sufficiently linear throughout the incubation period that initial and final concentrations could be used to calculate representative specific rates. These analyses demonstrated that specific thiosulfate oxidation rates were comparable under denitrifying and aerobic conditions $\left(0.43 \pm 0.005\right.$ and $0.56 \pm 0.006 \mu \mathrm{mol}$ thiosulfate $\cdot \min ^{-1} \cdot \mathrm{mg}$ protein ${ }^{-1}$ respectively).

RNA extraction. Immediately after exposures, two volumes of RNAprotect (QIAGEN) were added to each culture. Samples were incubated at room temperature for $12 \mathrm{~min}$, split in half, and centrifuged at 4,000 rpm for $10 \mathrm{~min}$. The supernatant was decanted, and the pellet was stored at $-20^{\circ} \mathrm{C}$ until extraction. RNA extraction was carried out with a MasterPure Complete (MPC) DNA and RNA purification kit (EpiCentre) using a modified protocol. Briefly, $300 \mu \mathrm{l}$ of lysis solution containing $112 \mu \mathrm{g}$ proteinase $\mathrm{K}$ was added to the cell pellet and the sample was incubated at $65^{\circ} \mathrm{C}$ for 20 to $25 \mathrm{~min}$. The sample was placed on ice for 3 to $5 \mathrm{~min}$, and $200 \mu \mathrm{l}$ of MPC solution was added to precipitate protein. The supernatant was recovered after centrifugation at $>10,000 \times g$ at $4^{\circ} \mathrm{C}$ for $10 \mathrm{~min}$ Nucleic acid was subsequently precipitated from the supernatant after addition of $500 \mu \mathrm{l} 99 \%$ isopropanol and centrifugation at $>10,000 \times g$ at $4^{\circ} \mathrm{C}$ for $10 \mathrm{~min}$. The pellet was treated with DNase I for $20 \mathrm{~min}$ at $37^{\circ} \mathrm{C}$. To this sample was added $200 \mu \mathrm{l}$ each of $2 \times \mathrm{T} \& \mathrm{C}$ lysis solution and MPC solution with vortexing after each addition. The samples were placed on ice for 3 to $5 \mathrm{~min}$ and centrifuged at $>10,000 \times g$ at $4^{\circ} \mathrm{C}$ for $10 \mathrm{~min}$. RNA in the supernatant was recovered by isopropanol precipitation as described above. The RNA pellet was washed twice with $75 \%$ ethanol, dried briefly, suspended in water, and stored at $-80^{\circ} \mathrm{C}$ until cDNA synthesis. Aliquots were analyzed with a Bioanalyzer (Agilent), which indicated minimal degradation and concentrations ranging from 310 to $2,000 \mathrm{ng} / \mu \mathrm{l} . A_{260} / A_{280}$ ratios ranged from 1.7 to 2.1 .

Preparation of labeled cDNA. cDNA production and labeling were performed by NimbleGen Systems, Inc. RNA samples were thawed on ice, and $10 \mu \mathrm{g}$ total RNA was used to perform cDNA synthesis with SuperScript II reverse transcriptase and random hexamers. After this reaction, RNases A and H were used to digest the RNA. Single-stranded cDNA was subsequently purified by phenol extraction. Glycogen $(10 \mu \mathrm{g})$ was added as a carrier prior to precipitation with a $1 / 10$ volume ammonium acetate and 2.5 volumes of absolute ethanol. The resulting pellet was suspended in $30 \mu \mathrm{l}$ water. The cDNA yield was determined by UV/visible spectrophotometry at $260 \mathrm{~nm}$. The cDNA was partially digested with DNase I $(0.2 \mathrm{U})$ at $37^{\circ} \mathrm{C}$ for $13 \mathrm{~min}$ or until 50 - to 200 -base fragments were observed with the Bioanalyzer. The fragmented cDNA was end labeled using biotin- $\mathrm{N}_{6}$-ddATP and terminal deoxynucleotidyl transferase $(51 \mathrm{U})$ with incubation at $37^{\circ} \mathrm{C}$ for $2 \mathrm{~h}$. The labeled product was concentrated to $20 \mu \mathrm{l}$ using a Microcon YM-10 10,000 MWCO filter device (Millipore) and frozen at $-20^{\circ} \mathrm{C}$ prior to hybridization.

Array design. The genome sequence from T. denitrificans ATCC 25259 (5) (GenBank accession no. CP000116) was submitted to NimbleGen Systems Inc. for microarray design and manufacture using maskless, digital micromirror technology. High-density (approximately 400,000-spot) microarrays employed a randomized design and a four-in-nine pattern to enhance sensitivity. Three replicates of the genome were included per chip. An average of 10 different 60-base oligonucleotides (60-mer probes) represented each open reading frame (ORF) in the genome. 60-mer probes were selected such that each probe had at least three mismatches compared to all other 60-mers in the target genome. A total of 28,320 probes were designed for the genome, which was annotated to have 2,832 ORFs at the time of microarray design (the finished genome is annotated to have 2,827 ORFs [5]). A quality control check (hybridization) was performed for each array, which contained on-chip control oligonucleotides.

Microarray hybridization and analysis. NimbleGen Systems, Inc. performed array hybridization using their Hybriwheel technology. The arrays were prehybridized at $45^{\circ} \mathrm{C}$ in a $50 \mathrm{mM}$ 4-morpholineethanesulfonic acid buffer containing $500 \mathrm{mM} \mathrm{NaCl}, 10 \mathrm{mM}$ EDTA, and $0.005 \%$ Tween 20 with herring sperm DNA $(0.1 \mathrm{mg} / \mathrm{ml})$ to prevent nonspecific binding to the array. After $15 \mathrm{~min}, 4 \mu \mathrm{g}$ of labeled cDNA in hybridization buffer was added and arrays were incubated at $45^{\circ} \mathrm{C}$ for 16 to $20 \mathrm{~h}$. Several wash steps (initially nonstringent and later stringent conditions) removed free probe, followed by detection of bound probe with Cy3-labeled streptavidin. To amplify the signal, biotinylated anti-streptavidin goat antibody was hybridized to the array. The arrays were analyzed using an Axon GenePix 4000B scanner with associated software (Molecular Devices Corp., Sunnyvale, CA).
Microarray data analysis. Investigation of reproducible differences between treatments was performed using the Bioconductor $\mathrm{R}$ software package. Data were processed using quantile normalization (7), and background correction was performed using the RMA (robust multiarray average) method. Data were visualized with box-and-whisker plots and scatter plots (volcano plots). Intensities were adjusted to have the same interquartile range. A linear model fit was determined for each gene using the LIMMA package (Linear Models for Microarray Data; Gordon K. Smyth), and lists of genes with the most evidence of differential expression were obtained.

Reverse transcription-quantitative PCR analysis. Confirmation of transcript levels for modulated genes was performed by reverse transcription-quantitative PCR (RT-qPCR) analysis of RNA samples representing each of the two experimental conditions. Total RNA from samples used for microarray analysis was reverse transcribed and amplified using a QuantiTect SYBR Green RT-PCR kit (QIAGEN) with gene-specific primers. Each gene-specific PCR was performed in triplicate using $25-\mu \mathrm{l}$ reaction mixtures containing $\sim 20 \mathrm{ng}$ of template on a Prism 7000 cycler (ABI). Calibration curves were performed with genomic DNA serially diluted over a range of 4 to 5 orders of magnitude. The PCR conditions were optimized to be performed as follows for all transcripts: $50^{\circ} \mathrm{C}$ for $30 \mathrm{~min}$; $95^{\circ} \mathrm{C}$ for $15 \mathrm{~min} ; 94^{\circ} \mathrm{C}$ for $15 \mathrm{~s}, 58^{\circ} \mathrm{C}$ for $30 \mathrm{~s}$, and $72^{\circ} \mathrm{C}$ for $30 \mathrm{~s} ; 30$ to 35 cycles. The primers are listed in Table S1 of the supplemental material.

RT-PCR analysis of $s q r$ and $\boldsymbol{d s r} C$ transcripts. Qualitative and quantitative RT-PCR studies were performed to investigate whether a gene associated with sulfur compound oxidation, $d s r C$ (Tbd1408), was cotranscribed with upstream genes associated with nitrate reduction (nar genes) and sulfide:quinone oxidoreductase (sqr; Tbd1407). Forward PCR primers were designed for Tbd1406 (narI) and Tbd1407 (Tbd1406F and Tbd1407F, respectively) (see Table S1 in the supplemental material), and reverse primers were designed for Tbd1408 (Tbd1408R and Tbd1408R2) (see Table S1). Control primers for the large transcript (targeting 1406 and 1407) and the Tbd1408 transcript were also designed and tested. The PCR conditions were optimized using $T$. denitrificans genomic DNA. cDNA was produced from RNA samples used in microarray experiments (aerobic and denitrifying conditions) with 150 to $250 \mathrm{ng}$ RNA (pretreated with DNase), 100 units Retroscript reverse transcriptase (Ambion), random decamers, and incubation at $43^{\circ} \mathrm{C}$ for $75 \mathrm{~min}$. PCR products were visualized by gel electrophoresis on a $1 \%$ agarose $1 \times$ Tris-acetate-EDTA gel with ethidium bromide staining and UV illumination. RT-qPCR analysis was performed with a forward primer from Tbd1407, the Tbd1407-1408 intergenic region, or Tbd1408 with a reverse primer for Tbd1408 (see Table S1). The primers and template were added to SYBR Green Master Mix (Bio-Rad), and reactions were run on a Cepheid SmartCycler using the following program: $98^{\circ} \mathrm{C}$ for $15 \mathrm{~s} ; 60^{\circ} \mathrm{C}$ for $60 \mathrm{~s} ; 40$ cycles. Controls for both RT-PCR and RT-qPCR analyses included trials without reverse transcriptase and trials without template.

Microarray data accession number. Microarray data have been deposited in the Gene Expression Omnibus database (http://www.ncbi.nlm.nih.gov/geo) under accession number GSE5256.

\section{RESULTS AND DISCUSSION}

Genome-wide observations. Microarray analysis identified 277 genes in $T$. denitrificans as differentially expressed under aerobic versus denitrifying conditions using a twofold cutoff $(P<0.0001)$. The top 50 upregulated genes under denitrifying conditions are listed in Table 1 , and the top 50 upregulated genes under aerobic conditions are listed in Table 2. A large percentage of the most upregulated genes under either denitrifying or aerobic conditions occur as gene clusters and can be classified within a small number of functional categories. To illustrate, under denitrifying conditions, upregulated genes include those associated with nitrate reductase (Tbd1401 to -1406 [Tbd1401-1406]; nar cluster), nitrite reductase (Tbd0070-0077; nir cluster), nitric oxide reductase (Tbd0554-0562; nor cluster), and sulfur compound oxidation (including Tbd1407-1408, adjacent to the nar cluster). Other gene clusters with less obvious functional associations are also included among the most upregulated genes (e.g., Tbd1499-1501 and Tbd1835-1838, which includes divergently transcribed genes) and certain functions are repre- 
TABLE 1. Top 50 ORFs upregulated under denitrifying conditions

\begin{tabular}{|c|c|c|c|c|}
\hline Tbd ORF & Fold upregulation & $\mathrm{p}$ value ${ }^{a}$ & Category $^{b}$ & Annotation $^{c}$ \\
\hline 1402 & 95 & $7.5 \mathrm{E}-37$ & DN NO3 & $\mathrm{NarK}_{2}$ protein, nitrate/proton antiporter \\
\hline 1404 & 94 & $2.4 \mathrm{E}-34$ & DN NO3 & NarH protein, nitrate reductase beta subunit \\
\hline 1403 & 89 & $1.8 \mathrm{E}-33$ & DN NO3 & NarG protein, nitrate reductase alpha subunit \\
\hline 1401 & 58 & $5.4 \mathrm{E}-56$ & DN NO3 & NarK protein, nitrate/proton symporter \\
\hline 1406 & 57 & $3.8 \mathrm{E}-52$ & DN NO3 & NarI protein, nitrate reductase gamma subunit \\
\hline 1407 & 55 & $3.4 \mathrm{E}-64$ & $\mathrm{~S}$ & Sulfide:quinone oxidoreductase \\
\hline 1405 & 54 & $9.5 \mathrm{E}-52$ & DN NO3 & NarJ protein, nitrate reductase chaperonin \\
\hline 2200 & 26 & $6.5 \mathrm{E}-36$ & & Fimbrial protein PilA \\
\hline 2774 & 25 & $2.0 \mathrm{E}-46$ & Null & Null \\
\hline 0077 & 21 & 2.9E-40 & $\mathrm{DN} \mathrm{NO} 2$ & NirS (cytochrome $c d_{1}$ ), nitrite reductase \\
\hline 0073 & 20 & $1.4 \mathrm{E}-31$ & DN NO2 & NirG protein \\
\hline 2012 & 18 & $1.4 \mathrm{E}-37$ & $\mathrm{~S}$ & Sulfate thiol esterase (tentative) \\
\hline 0075 & 14 & $1.5 \mathrm{E}-39$ & DN NO2 & NirF protein \\
\hline 0072 & 14 & $1.4 \mathrm{E}-38$ & $\mathrm{DN} N O 2$ & Nitrite reductase heme biosynthesis protein $\mathrm{NirH}$ \\
\hline 1408 & 14 & $4.0 \mathrm{E}-32$ & $\mathrm{~S}$ & Putative DsrC protein \\
\hline 0076 & 13 & $2.2 \mathrm{E}-33$ & DN NO2 & Probable NirC protein \\
\hline 1835 & 13 & $1.4 \mathrm{E}-37$ & & Blr3518 protein \\
\hline 1649 & 13 & $9.9 \mathrm{E}-33$ & S? & Null \\
\hline 0071 & 12 & $1.6 \mathrm{E}-37$ & DN NO2 & Heme D1 biosynthesis protein NirJ \\
\hline 0070 & 12 & $2.2 \mathrm{E}-37$ & $\mathrm{DN} \mathrm{NO} 2$ & Probable NirN protein \\
\hline 2226 & 11 & $7.6 \mathrm{E}-32$ & S? & Null \\
\hline 2175 & 11 & $3.5 \mathrm{E}-35$ & & Hypothetical protein \\
\hline 0074 & 11 & $8.9 \mathrm{E}-40$ & DN NO2 & NirD protein \\
\hline 2688 & 10 & $2.4 \mathrm{E}-51$ & & TonB-dependent receptor protein \\
\hline 0561 & 9.5 & $4.8 \mathrm{E}-22$ & DN NO & Nitric oxide reductase subunit B (NorB) \\
\hline 1836 & 8.9 & $1.4 \mathrm{E}-28$ & & Putative RNA polymerase sigma factor \\
\hline 0576 & 8.9 & $2.6 \mathrm{E}-38$ & & Putative long-chain-fatty-acid transport protein \\
\hline 0559 & 8.9 & $1.9 \mathrm{E}-35$ & DN NO & Null \\
\hline 0562 & 8.7 & $1.3 \mathrm{E}-37$ & DN NO & Nitric oxide reductase subunit C (NorC) \\
\hline 1650 & 8.7 & $5.3 \mathrm{E}-27$ & $\mathrm{~S}$ & Rhodanese-like domain protein \\
\hline 0558 & 8.3 & $1.2 \mathrm{E}-32$ & DN NO & Probable NorQ protein \\
\hline 1837 & 8.2 & $2.5 \mathrm{E}-40$ & & Hypothetical signal peptide protein \\
\hline 0557 & 7.1 & $5.8 \mathrm{E}-40$ & DN NO & Hypothetical protein \\
\hline 0554 & 7.0 & $3.8 \mathrm{E}-34$ & DN NO? & Null \\
\hline 2225 & 6.5 & 4.7E-31 & $\mathrm{S}$ & Sulfide:quinone oxidoreductase \\
\hline 2638 & 6.0 & $1.3 \mathrm{E}-24$ & $\mathrm{CO} 2$ & RubisCO form II protein, CbbM \\
\hline 1501 & 5.9 & $1.1 \mathrm{E}-10$ & Null & Null \\
\hline 2327 & 5.7 & $2.0 \mathrm{E}-20$ & $\mathrm{~S}$ & Putative DsrC protein \\
\hline 2317 & 5.6 & $3.6 \mathrm{E}-35$ & & Rubrerythrin/nigerythrin-like protein \\
\hline 0555 & 5.5 & 7.7E-25 & DN NO & Possible NorD protein \\
\hline 1742 & 5.4 & $5.4 \mathrm{E}-21$ & & $\mathrm{~F}_{1}$-ATP synthase, epsilon subunit \\
\hline 1367 & 4.6 & $5.4 \mathrm{E}-26$ & & Predicted periplasmic or secreted lipoprotein \\
\hline 0556 & 4.6 & $4.0 \mathrm{E}-27$ & DN NO & Iron-sulfur cluster-binding protein \\
\hline 1809 & 4.4 & $3.8 \mathrm{E}-37$ & & Plasmid-related protein \\
\hline 1500 & 4.4 & 7.7E-19 & & V-type $\mathrm{H}^{+}$-translocating pyrophosphatase \\
\hline 1388 & 4.3 & $3.2 \mathrm{E}-12$ & & Cystathionine beta-synthase domain protein \\
\hline 1739 & 4.3 & $6.8 \mathrm{E}-26$ & TT & Tetrathionate reductase subunit $\mathrm{B}$ \\
\hline 1741 & 4.3 & $6.3 \mathrm{E}-27$ & TT & Tetrathionate reductase subunit $\mathrm{A}$ \\
\hline 1499 & 4.3 & $8.3 \mathrm{E}-25$ & & Hypothetical protein \\
\hline 0907 & 4.0 & 3.7E-27 & & Bacterial neuraminidase repeat \\
\hline
\end{tabular}

${ }^{a}$ The p values were adjusted by procedures to control the FDR (false discovery rate) criterion defined by Benjamini and Hochberg (6).

${ }^{b}$ Category definitions: DN NO3, denitrification, nitrate reductase; DN NO2, denitrification, nitrite reductase; DN NO, denitrification, nitric oxide reductase; S, sulfur compound oxidation; TT, tetrathionate reductase; $\mathrm{CO} 2, \mathrm{CO}_{2}$ fixation via RubisCO. "Null" indicates no good hits and no clues from context; "?" indicates no good hits but location and expression suggest association with adjacent genes of known function.

${ }^{c}$ Best attempt at annotation based on examination of best BLASTP matches and genomic context.

sented by single genes (e.g., $c b b M$, which encodes form II RubisCO). Under aerobic conditions, upregulated genes include a large cluster putatively encoding proteins associated with iron acquisition (Tbd0705-0725, which account for more than $40 \%$ of the top 50 upregulated genes), a cytochrome $c b b_{3}$ oxidase (Tbd0638-0643), multiple chaperones (including Tbd1537-1539), and form I RubisCO ( $c b b S$ and $c b b L$; Tbd2623-2624). Under aerobic conditions, as under denitrifying conditions, gene clusters with less obvious functional associations are also included among the most up- regulated genes (e.g., Tbd2355-2358, Tbd2592-2594, and Tbd2777-2778) (Table 2), and certain functions are represented by single genes (e.g., Tbd1365, a putative $d s r C$ presumably associated with sulfur compound oxidation).

The observation that a relatively small number of functional categories account for the majority of the most differentially expressed genes is apparent in Fig. 1, which plots $\log _{2}$ probability of differential expression versus $\log _{2}$ fold differential expression for all ORFs identified in the genome. The color coding in Fig. 1 corresponds to the major categories listed in 
TABLE 2. Top 50 ORFs upregulated under aerobic conditions

\begin{tabular}{|c|c|c|c|c|}
\hline Tbd ORF & Fold upregulation & $\mathrm{p}$ value ${ }^{a}$ & Category $^{b}$ & Annotation $^{c}$ \\
\hline 0725 & 159 & 2.3E-78 & $\mathrm{Fe}$ & Putative hemin uptake protein HemP \\
\hline 0706 & 117 & $2.0 \mathrm{E}-63$ & $\mathrm{Fe}$ & Anion-specific porin \\
\hline 0722 & 111 & 7.9E-59 & $\mathrm{Fe}$ & Possible PvuA protein, polyhydroxycarboxylate siderophore uptake \\
\hline 0705 & 73 & 4.2E-51 & $\mathrm{Fe}$ & Bacterioferritin-associated ferredoxin \\
\hline 0721 & 61 & 3.4E-54 & $\mathrm{Fe}$ & Possible PvsA protein, ferritin biosynthesis protein \\
\hline 0710 & 57 & 2.1E-57 & $\mathrm{Fe}$ & Putative lipoprotein \\
\hline 0715 & 46 & $7.5 \mathrm{E}-67$ & $\mathrm{Fe}$ & Possible PsuA protein, TonB-dependent receptor \\
\hline 0718 & 43 & $1.2 \mathrm{E}-59$ & $\mathrm{Fe}$ & Possible PvsD protein, ferritin biosynthesis protein \\
\hline 0712 & 40 & $8.5 \mathrm{E}-59$ & $\mathrm{Fe}$ & MotA/TolQ/ExbB proton channel family \\
\hline 0724 & 37 & $3.4 \mathrm{E}-43$ & $\mathrm{Fe} ?$ & Null \\
\hline 0720 & 31 & 7.2E-46 & $\mathrm{Fe}$ & Possible PvsB protein, ferritin biosynthesis protein \\
\hline 0709 & 27 & $2.0 \mathrm{E}-48$ & $\mathrm{Fe}$ ? & Putative signal peptide protein \\
\hline 0723 & 27 & 7.3E-50 & $\mathrm{Fe}$ & Possible high-affinity $\mathrm{Fe}^{2+} / \mathrm{Pb}^{2+}$ permease \\
\hline 0711 & 25 & 5.7E-55 & $\mathrm{Fe}$ & ExbD/TolR proton channel family \\
\hline 0716 & 24 & $6.2 \mathrm{E}-64$ & $\mathrm{Fe}$ & Putative aldolase, ferritin biosynthesis protein \\
\hline 0717 & 23 & 8.6E-41 & $\mathrm{Fe}$ & Possible PvsE protein, ferritin biosynthesis protein \\
\hline 1078 & 18 & 3.4E-50 & Chap & Heat shock family protein HtpG \\
\hline 0719 & 14 & 3.8E-52 & $\mathrm{Fe}$ & Possible PvsC protein, siderophore efflux protein \\
\hline 0641 & 14 & 3.1E-34 & CytOx & $c b b_{3}$-type cytochrome oxidase subunit IV (CcoQ) \\
\hline 2777 & 13 & 3.3E-35 & & Hypothetical protein \\
\hline 2778 & 12 & 4.7E-33 & & Predicted outer membrane lipoprotein \\
\hline 1252 & 11 & $8.1 \mathrm{E}-44$ & Chap & Probable ATP-dependent Lon protease \\
\hline 0815 & 9.6 & 1.1E-36 & Chap & ClpB ATPase-dependent protease \\
\hline 0708 & 9.6 & $1.6 \mathrm{E}-39$ & $\mathrm{Fe}$ ? & Possible ApbE protein \\
\hline 0643 & 9.6 & $1.7 \mathrm{E}-41$ & CytOx & $c b b_{3}$-type cytochrome oxidase subunit I $(\mathrm{CcoN})$ \\
\hline 0713 & 9.4 & $1.6 \mathrm{E}-35$ & $\mathrm{Fe}$ & Possible TonB-like energy transducer \\
\hline 1538 & 9.2 & 1.3E-17 & Chap & Chaperone protein DnaK \\
\hline 2593 & 9.2 & $1.0 \mathrm{E}-31$ & & Putative transcriptional regulator \\
\hline 0091 & 9.1 & 2.7E-30 & Chap & Chaperonin GroEL (HSP60 family) \\
\hline 0640 & 8.8 & 7.1E-39 & CytOx & $c b b_{3}$-type cytochrome oxidase subunit III (CcoP) \\
\hline 1053 & 7.8 & $2.9 \mathrm{E}-35$ & & Hypothetical protein \\
\hline 2624 & 7.4 & $9.2 \mathrm{E}-29$ & $\mathrm{CO} 2$ & RubisCO form I protein, CbbL (large subunit) \\
\hline 0638 & 7.4 & $1.6 \mathrm{E}-24$ & CytOx & $\mathrm{cbb}_{3}$ cytochrome oxidase maturation protein $\mathrm{CcoH}$ \\
\hline 1420 & 7.4 & $1.1 \mathrm{E}-40$ & & $\mathrm{ABC}$ transporter phosphate-binding protein \\
\hline 0714 & 7.1 & 5.1E-37 & $\mathrm{Fe}$ & Uncharacterized iron-regulated membrane protein \\
\hline 1585 & 7.0 & $7.8 \mathrm{E}-39$ & & Radical SAM enzyme of unknown function \\
\hline 1365 & 6.9 & $2.8 \mathrm{E}-29$ & $\mathrm{~S}$ & Putative DsrC protein \\
\hline 2357 & 6.8 & $3.2 \mathrm{E}-26$ & & Hypothetical protein \\
\hline 2356 & 6.6 & $6.6 \mathrm{E}-25$ & & Hypothetical protein \\
\hline 2623 & 6.5 & $1.0 \mathrm{E}-27$ & $\mathrm{CO} 2$ & RubisCO form I protein, CbbS (small subunit) \\
\hline 2398 & 6.4 & 7.4E-36 & & Hypothetical protein \\
\hline 0194 & 6.4 & 7.3E-31 & Null & Null \\
\hline 2401 & 6.4 & 4.9E-15 & & Thioredoxin domain-containing protein \\
\hline 1370 & 6.3 & $3.1 \mathrm{E}-16$ & Chap & Chaperone protein IbpA (small heat shock protein) \\
\hline 2270 & 6.1 & 4.6E-36 & & Porcine attaching-effacing-associated protein variant 1 \\
\hline 2355 & 6.1 & $5.9 \mathrm{E}-28$ & Null & Null \\
\hline 0707 & 6.1 & $2.9 \mathrm{E}-40$ & $\mathrm{Fe}$ ? & Probable transmembrane protein \\
\hline 0043 & 5.9 & $5.5 \mathrm{E}-32$ & & Hypothetical protein \\
\hline 1539 & 5.7 & $3.1 \mathrm{E}-34$ & Chap & Chaperone protein DnaJ \\
\hline 2592 & 5.7 & $5.9 \mathrm{E}-29$ & & Putative membrane protein \\
\hline
\end{tabular}

${ }^{a}$ The $\mathrm{p}$ values were adjusted by procedures to control the FDR criterion defined by Benjamini and Hochberg (6).

${ }^{b}$ Category definitions: Fe, iron acquisition; Chap, chaperones and stress proteins; CytOx, cytochrome oxidase; $\mathrm{CO}_{2}$, $\mathrm{CO}_{2}$ fixation via RubisCO; $\mathrm{S}$, sulfur compound oxidation. "Null" indicates no good hits and no clues from context; "?" indicates no good hits but location and expression suggest association with adjacent genes of known function.

${ }^{c}$ Best attempt at annotation based on examination of best BLASTP matches and genomic context.

Tables 1 and 2, namely, denitrification, sulfur compound oxidation, $\mathrm{CO}_{2}$ fixation via RubisCO (forms I and II), iron acquisition, cytochrome $c b b_{3}$ oxidase, and chaperones and stress proteins; all genes not falling within these categories in Tables 1 and 2, and all genes not included in Tables 1 and 2, are gray in Fig. 1.

Denitrification. Although it is not surprising that genes associated with denitrification (nar, nir, and nor genes) were among the most upregulated genes under denitrifying conditions, subtler trends in expression of these genes were more novel. Most notably, relative expression levels (i.e., degree of upregulation under denitrifying conditions) tended to decrease in the order nar $>$ nir $>$ nor $>$ nos (Fig. 2). With the exception of a few genes (primarily associated with transcriptional regulators, such as narXL and Tbd0078-0079), fold upregulation for denitrification genes fell in the following ranges: nar, 54- to 95-fold; nir, 10- to 21-fold; nor, 4- to 10-fold; nos, 0.5- to 0.9 -fold. This trend was both a function of generally decreasing absolute expression levels under denitrifying conditions (except for the structural genes nirS, norCB, and nos $Z$ ) and in- 


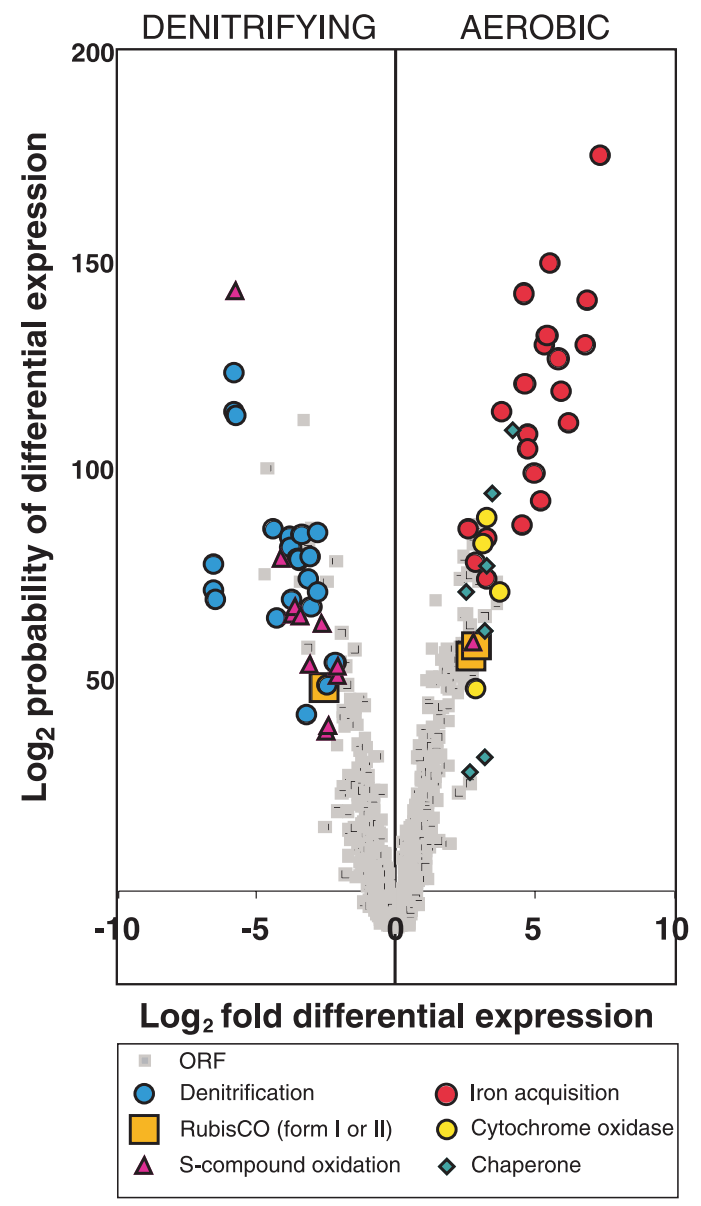

FIG. 1. Plot of $\log _{2}$ probability of differential expression versus $\log _{2}$ fold differential expression for all genes identified in the T. denitrificans genome. The color coding corresponds to the major categories listed in Tables 1 and 2, namely, denitrification, sulfur compound oxidation, $\mathrm{CO}_{2}$ fixation via RubisCO (forms I and II), iron acquisition, cytochrome $c b b_{3}$ oxidase, and chaperones and stress proteins; all genes not falling within these categories in Tables 1 and 2, as well as all genes not included in Tables 1 and 2, are colored gray.

creased expression of nos genes (especially nos $Z$ ) under aerobic conditions (Fig. 2).

To our knowledge, this is the most complete data set for differential aerobic/denitrifying expression across the complement of denitrification genes; previous transcriptional studies have focused primarily on structural genes or on gene clusters associated with only one of the four denitrification enzymes. In a general sense, the microarray results for $T$. denitrificans are consistent with the well-documented transcriptional activation of denitrification genes as a function of low $\mathrm{O}_{2}$ tension and the presence of a nitrogen oxide $\left(\mathrm{NO}_{3}{ }^{-}, \mathrm{NO}_{2}{ }^{-}, \mathrm{NO}\right.$, or $\left.\mathrm{N}_{2} \mathrm{O}\right)$ (reviewed in reference 36 ). With respect to $T$. denitrificans specifically, the microarray results are generally consistent with greatly increased NAR and NIR enzyme activities (in crude extracts) that were observed to accompany the transition from aerobic to denitrifying conditions in continuous culture (18). Furthermore, the decreasing trend in upregulation shown in Fig. 2 could be consistent with induction of each reductase component by its cognate substrate, as one might expect the

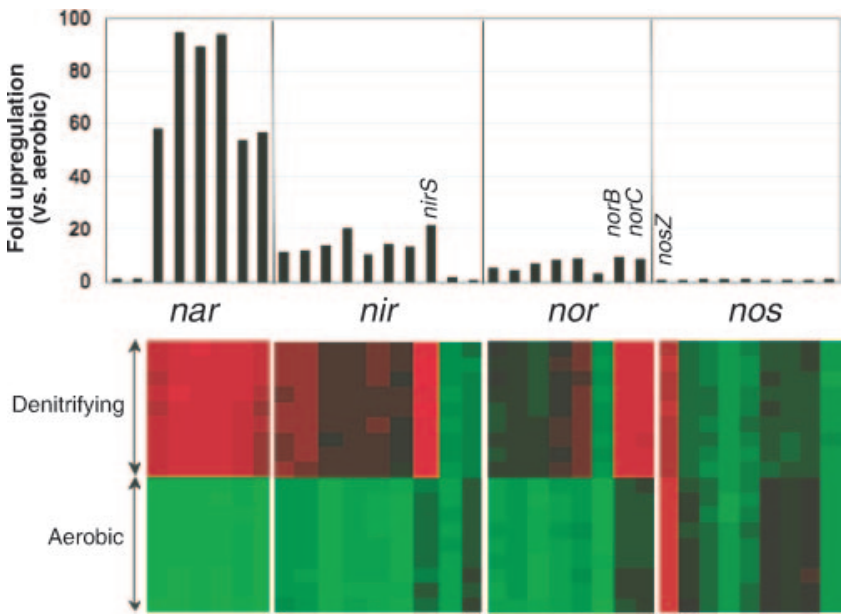

FIG. 2. Histogram displaying fold upregulation (denitrifying versus aerobic conditions) for genes associated with denitrification, including nar cluster genes (Tbd1399-1406), nir cluster genes (Tbd0070-0079), nor cluster genes (Tbd0555-0562), and nos cluster genes (Tbd1389-1397). Structural nir, nor, and nos genes are labeled. Absolute expression levels for these genes are shown below the histogram, with green representing the lowest levels of expression, black representing intermediate levels, and red representing the highest levels. The plot of absolute expression levels shows all nine replicates for each condition.

concentration pattern of $\left[\mathrm{NO}_{3}{ }^{-}\right]>\left[\mathrm{NO}_{2}{ }^{-}\right]>[\mathrm{NO}]>\left[\mathrm{N}_{2} \mathrm{O}\right]$ in a denitrifying cell (although this concept clearly oversimplifies the regulation of denitrification).

However, for nos genes in particular, the results for T. denitrificans appear to deviate from findings for other denitrifying species for which data are available, namely, Pseudomonas stutzeri, Paracoccus denitrificans, and Paracoccus pantotrophus (formerly Thiosphaera pantotropha). For example, whereas expression of nos genes (including nosD) in T. denitrificans was comparable under aerobic and denitrifying conditions, the amount of nos $D$ transcripts in $P$. stutzeri (revealed by Northern blot analysis) increased steadily and dramatically during the first hour following a shift from aerobic to denitrifying conditions in continuous culture (15). In another continuous culture study of $P$. stutzeri (20), NosZ levels were at least 10 -fold greater for cells under denitrifying conditions than for cells under fully aerobic conditions (in the presence of nitrate). A continuous culture study of Paracoccus denitrificans revealed more than a 10 -fold increase in the amount of nos $Z$ transcripts during the first hour following transition from aerobic to denitrifying conditions (3). This temporal trend was qualitatively similar to those of other denitrification genes; however, narH and nirS transcript copy numbers increased more (approximately 30- to 45-fold) (3). In continuous culture and batch culture studies of $P$. pantotrophus (23), NosZ expression was 2to ca. 20-fold greater under denitrifying conditions than under aerobic conditions (in the presence or absence of nitrate) and clearly decreased as a function of increasing oxygen concentration in continuous culture. Differences in experimental approach preclude a direct comparison of the results of the present study with those just cited for $P$. stutzeri and $P$. denitrificans; such differences in experimental approach include the use of continuous cultures versus batch cultures and measurement after aerobic/anaerobic transitions versus comparisons of 
cultures grown exclusively under aerobic or denitrifying conditions. Acknowledging this caveat, the available data suggest inconsistent trends for differential aerobic/denitrifying nos gene expression in $T$. denitrificans compared to other species studied. In $P$. stutzeri, $P$. denitrificans, and $P$. pantotrophus, there appears to be considerable upregulation of nos genes (at least nos $Z$ and nos $D$ ) under denitrifying conditions; this is clearly not the case for $T$. denitrificans (indeed, there is slight upregulation of these genes under aerobic conditions) (Fig. 2).

In the absence of additional experimental evidence, we cannot explain the anomalous lack of differential transcription of nos $Z$ and other nos genes in T. denitrificans under aerobic versus denitrifying conditions. Nonetheless, examination of promoter regions for some key genes associated with denitrification did reveal possible clues. Specifically, these promoter regions in $T$. denitrificans were examined with respect to potential FNR boxes (i.e., DNA-binding motifs for FNR-like transcription factors). When compared to the canonical FNR

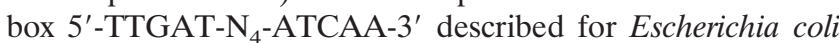
(36), slightly degenerate sequences were found upstream of narK (aTGAc...ATCtt, located 778 nucleotides [nt] from the translational start site of Tbd1401), nirS (TTGAc...ATCAA, located $76 \mathrm{nt}$ from the translational start site of Tbd0077), norC (aTGAc...ATCAA, located $163 \mathrm{nt}$ from the translational start site of Tbd0562), and nosZ (TTGAg...gTCAg, located 1,310 nt from the translational start site of Tbd1389). Two features shared by the narK, nirS, and nor C versions and not in the nos $Z$ version are the $\mathrm{c}$ and A shown in boldface type above. Also, upstream of $\operatorname{nos} Z$, there were five additional sequences with $5^{\prime}$ ends that matched either the canonical FNR box or the narK, nirS, or norC FNR boxes cited above, but these were more degenerate on the $3^{\prime}$ end (with only 0 to 2 bases agreeing with the canonical sequence). Degeneracy at the $3^{\prime}$ end of FNR boxes upstream of nos $Z$ has been observed for some denitrifying species $(8,36)$ but not for others $(2)$. Considering that FNR boxes for positive regulation of denitrification genes are typically centered at a distance of $-41.5 \mathrm{nt}$ from the transcription start site (36), most of the putative FNR boxes just described for $T$. denitrificans seem to be very far upstream. It is not clear whether any of these characteristics of putative FNR boxes in T. denitrificans could explain the lack of $n o s Z$ upregulation under denitrifying conditions.

Sulfur compound oxidation. Although a diverse complement of more than 50 genes associated with sulfur compound oxidation has been described in T. denitrificans ATCC 25259 (5), those genes associated with activity under aerobic versus denitrifying conditions have not been elucidated to date. Many of the $T$. denitrificans genes associated with sulfur compound oxidation (5) were not found to be differentially expressed in this study (Tables 1 and 2). Among the genes not appearing in Tables 1 and 2 were clusters of sulfur compound oxidation genes that were very highly expressed under both aerobic and denitrifying conditions. These include soxXYZA (Tbd05670564), dsrABEFHCMKLJOP (Tbd2485-2474), and the genes encoding ATP sulfurylase and APS reductase (Tbd0874-0872). The expression levels of these genes were typically at or above the 95th percentile expression level observed across the genome. Indeed, many of these genes are likely to be constitutively expressed in $T$. denitrificans as, in most cases, their expression levels were similarly high under Fe(II)-oxidizing, denitrifying conditions when no sulfur-containing electron donor was present $(\mathrm{H}$. Beller et al., unpublished microarray data).

Differential expression was observed for certain genes associated with sulfur compound oxidation; in some cases, the absolute expression levels of these genes when upregulated were also in the range of the 95th percentile expression level observed across the genome. Among the most differentially regulated genes putatively associated with sulfur compound oxidation, all but one were upregulated under denitrifying rather than aerobic conditions (Tables 1 and 2; Fig. 1). These included two copies of sulfide:quinone oxidoreductase (sqr) that share $43 \%$ amino acid identity (Tbd1407 and Tbd2225; 55and 6.5-fold upregulated under denitrifying conditions), a rhodanese-like domain protein (Tbd1650; 8.7-fold upregulated), and two putative copies of $d s r C$ that share $88 \%$ amino acid identity (Tbd1408 and Tbd2327; 14- and 5.7-fold upregulated). Another putative copy of $d s r C$ (Tbd1365) was upregulated 6.9-fold aerobically. Another rhodanese copy (Tbd2399) was less upregulated aerobically (3.8-fold) but was included in a gene cluster that exhibited some stronger aerobic upregulation (Tbd2398-2401) (Table 2).

Inasmuch as three $d s r C$ copies were among the most differentially regulated genes, it is noteworthy that the $T$. denitrificans genome includes eight putative $d s r C$ copies overall (5); the phylogenetic relationships and genomic organization of these homologs have been presented elsewhere (5). Only one copy, Tbd2480, is located in the large gene cluster $d s r A B E F$ HCMKLJOPNR (Tbd2485-2472) and is constitutively expressed at a high level (5). Although the exact function of DsrC is not known, it is almost certainly involved with sulfur compound oxidation; the associated $d s r A B$ genes encode a siroheme-containing sulfite reductase that has been proposed to catalyze the oxidation of certain inorganic sulfur species (e.g., hydrogen sulfide or sulfane-sulfur derived from thiosulfate) to sulfite $(27,33)$.

In light of the strong upregulation of Tbd1407 (sqr) and Tdb1408 (putative $d s r C$ ) under denitrifying conditions (Table $1)$, the genomic location of these genes is noteworthy: they are immediately downstream of the narKK $K_{2} G H J I$ cluster (Tbd1401 -1406) (5), which encodes a membrane-bound, dissimilatory nitrate reductase (and associated nitrate/nitrite transporters) (Fig. 3A). As there is not even a single intergenic base separating Tbd1406 and Tbd1407, it follows that Tbd1407 is part of a polycistronic transcript including nar genes (probably narKK $\left.K_{2} G H J I\right)$. However, the intergenic region between Tbd1407 and Tbd1408 includes a putative ribosomal-binding site and FNR box (Fig. 3B). Thus, coregulation rather than cotranscription of Tbd1407 and Tbd1408 is plausible and, indeed, is suggested by the anomalously high expression of Tbd1408 relative to Tbd1407 under aerobic conditions (Fig. 3A). To further investigate whether Tbd1408 was transcribed independently of Tbd1407 and upstream nar genes, RT-qPCR studies were conducted. These studies confirmed that, for the most part, Tbd1408 was transcribed separately from Tbd1407 and upstream nar genes: under denitrifying or aerobic conditions, the copy number of transcripts of Tbd1408 ( $d s r C)$ was at least 10 -fold greater than the copy number of transcripts including Tbd1407 and Tbd1408 (sqr and $d s r C$ ) (Fig. 3C). Although the RT-qPCR studies were constrained by amplicon length and did 


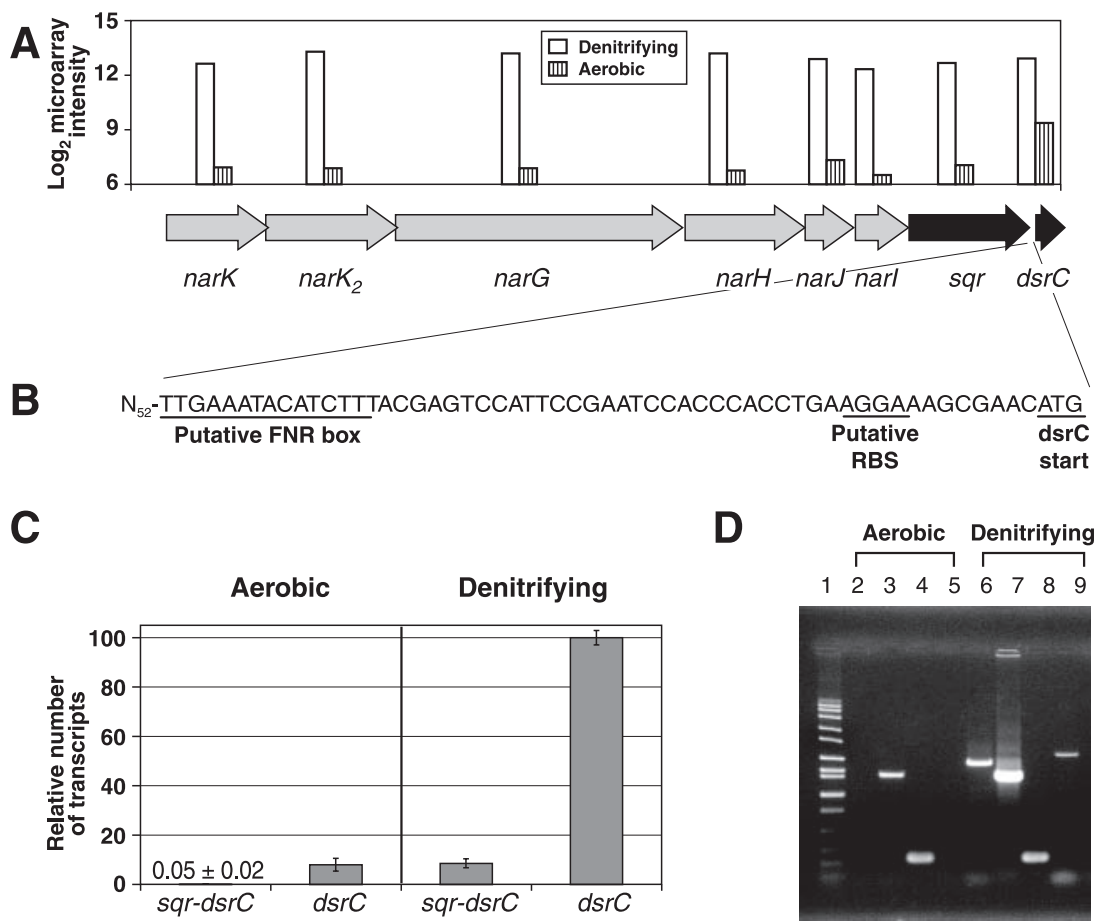

FIG. 3. (A) Histogram of absolute expression levels of $s q r$ (Tbd1407), dsrC (Tbd1408), and adjacent nar genes under aerobic and denitrifying conditions. (B) Partial sequence of the intergenic region between $s q r$ and $d s r C$; the putative ribosomal-binding site (RBS) and FNR box are indicated by underlining. (C) RT-qPCR results for cells exposed to aerobic and denitrifying conditions showing the relative number of transcripts that include $d s r C$ (primers Tbd1408F and Tbd1408R2) or $d s r C$ plus the intergenic region between $s q r$ and $d s r C$ (primers Tbd1407-1408IG_F and Tbd1408R). Numbers of transcripts are normalized to the largest value ( $d s r C$; denitrifying conditions). Error bars represent 1 standard deviation based upon triplicate analyses. (D) Electropherogram of RT-PCR products from RNA extracts for cells exposed to aerobic (lanes 2 to 5) and denitrifying (lanes 6 to 9) conditions. Lane 1, Hi-Lo DNA marker, 50 bp to $10 \mathrm{kbp}$ (Bionexus Inc., Oakland, CA); lanes 2 and 6, Tbd1407F/ Tbd1408R2; lanes 3 and 7, Tbd1407F/Tbd1407R; lanes 4 and 8, Tbd1408F/Tbd1408R2; lanes 5 and 9, Tbd1406F/Tbd1408R2. All bands represent cDNA amplicons of the expected length and are consistent with PCRs using genomic DNA as the template (not shown). No bands were visible for negative controls lacking reverse transcriptase (not shown).

not address transcripts extending upstream beyond Tbd1407, semiquantitative RT-PCR analyses (Fig. 3D) suggested that, at least under denitrifying conditions, the Tbd1407-1408 transcripts actually extended at least from Tbd1406 (narI) to Tbd1408 (lane 9). Overall, the microarray and RT-qPCR results suggest that the promoter(s) controlling the expression of $d s r C$ (Tbd1408), while clearly effecting stronger activation under denitrifying than aerobic conditions, may be further enhanced by the presence of sulfur compounds.

Carbon dioxide fixation. The genome of $T$. denitrificans encodes both form I and form II RubisCO enzymes for $\mathrm{CO}_{2}$ fixation $(11,14)$. The microarray results show clearly that the structural genes encoding form I and II RubisCO were differentially expressed: $c b b M$ (Tbd2638, which encodes form II) was upregulated 6-fold under denitrifying conditions (Table 1), whereas $c b b L$ and $c b b S$ (Tbd2624-2623, which encode the large and small subunits of form I) were upregulated 7.4- and 6.5-fold, respectively, under aerobic conditions (Table 2). The other $c b b$ genes included in the form I and form II RubisCO gene clusters were also differentially expressed, albeit to a lesser extent than the structural genes. Thus, $c b b Q$ and $c b b O$ (Tbd2637 and Tbd2636) in the form II cluster were upregulated 2.7- and 3.5-fold under denitrifying conditions, whereas their homologs in the form I cluster (Tbd2622 and Tbd2621) were upregulated 5.5- and 2.6-fold under aerobic conditions.
These results are consistent with the biochemical characterization of form I and II RubisCO in T. denitrificans with respect to their relative affinities to $\mathrm{CO}_{2}$ and $\mathrm{O}_{2}$. Molecular oxygen competes with $\mathrm{CO}_{2}$ for the active site of RubisCO and thereby decreases its efficiency for carbon fixation. The relative specificity of RubisCO enzymes for $\mathrm{CO}_{2}$ and $\mathrm{O}_{2}$ (the $\mathrm{CO}_{2} / \mathrm{O}_{2}$ specificity factor, or $\tau$ ) was determined in T. denitrificans (14); form I was shown to have considerably higher $\mathrm{CO}_{2} / \mathrm{O}_{2}$ specificity $(\tau$ $=46)$ than form II $(\tau=14)$. Thus, expressing form I under aerobic conditions would tend to maximize the efficiency of $\mathrm{CO}_{2}$ fixation.

We are not aware of any previous studies of differential expression of form I and II RubisCO under aerobic versus denitrifying conditions. The most relevant studies are those that investigated expression of form I and II RubisCO under a variety of chemoautotrophic, chemoheterotrophic, photoautotrophic, and photoheterotrophic conditions in Rhodobacter sphaeroides and Rhodobacter capsulatus (recently reviewed in reference 10). Differential transcription of forms I and II was observed in some of these studies. In the absence of more experimental data for $T$. denitrificans, these existing studies allow us only to speculate about regulatory systems that might be involved in differential transcription of form I and II RubisCO in T. denitrificans.

$\mathrm{RegB} / \mathrm{RegA}$ is a global, two-component, redox-responsive 
regulatory system that appears to have a role in differential expression of form I and II RubisCO in Rhodobacter species (reference 10 and references therein). For example, in work with reg $A$ mutants of $R$. sphaeroides grown under aerobic, chemoautotrophic conditions, Gibson et al. (12) indicated that RegA (PrrA) functioned as a strong activator of form II RubisCO genes but had no effect on, or acted as a mild repressor of, the form I genes. However, rocket electroimmunoassay studies of $R$. sphaeroides strain HR-CAC showed that approximately 2.5-fold more form I than form II RubisCO protein was expressed under aerobic chemolithoautotrophic conditions (25). RegA also influences the differential, redoxresponsive transcription of other genes, including those associated with photosynthesis, cytochrome $c b b_{3}$ oxidase, and $\mathrm{Cu}$-containing nitrite reductase (nirK).

Several lines of evidence suggest that the RegB/RegA system is present in $T$. denitrificans and may contribute to transcriptional regulation of RubisCO genes: (i) genes putatively encoding RegA and RegB have been identified in $T$. denitrificans (Tbd2690 and Tbd2689, respectively), (ii) possible RegA-binding sites are present upstream of $c b b M$ and $c b b L$, and (iii) at least one putative RegA-binding site is present in the intergenic region upstream of the aerobically upregulated $c c o N$ gene (Tbd0643), which encodes a subunit of cytochrome $c b b_{3}$ oxidase and has been associated with $\mathrm{RegB} / \mathrm{RegA}$ regulation in $R$. capsulatus $(29,30)$. BLASTP searches for RegA in the $T$. denitrificans genome using the RegA (PrrA) sequence from $R$. sphaeroides (GenBank YP 351562) revealed that Tbd2690 was the best match; the deduced amino acid sequence of Tbd2690 shares 51\% identity with the RegA sequence of $R$. sphaeroides. Alignment of these (and other) RegA sequences showed that the $T$. denitrificans homolog also includes the highly conserved helix-turn-helix DNA-binding motif described for a range of RegA homologs (10). RegB is putatively encoded by Tbd2689 in T. denitrificans (26\% sequence identity with the RegB sequence of $R$. sphaeroides; GenBank YP_351564). Alignment of the deduced amino acid sequence of Tbd2689 with known RegB sequences revealed that the $T$. denitrificans homolog contains a highly conserved, redox-active cysteine residue that has been shown to exert control over the activity of the sensor kinase in $R$. sphaeroides (31). Searches for RegA-binding sites upstream of $c b b M$ and $c b b L$ in $T$. denitrificans revealed possible degenerate sequences. Laguri et al. (22) described the following main features of RegA-binding sites derived from studies of $R$. sphaeroides and $R$. capsulatus: (i) a palindromic 5'-GCGNC...GNCGC-3' consensus, (ii) a central AT-rich section, and (iii) a variable number of bases between the $5^{\prime}$ and $3^{\prime}$ palindromic regions (with an apparent total of 9 to 15 bases in the binding site motif). Sequences conforming to these characteristics were found upstream of $c b b M\left(5^{\prime}\right.$-GCGACAGCCGC-3') and $c b b L$ (5'-GCGCCTCTT GTCGC-3'). Notably, both of these putative RegA-binding sites were located at least $950 \mathrm{nt}$ upstream of the translational start sites of $c b b M$ and $c b b L$ and occurred in a complementary $c b b R$ coding region (i.e., in a $c b b R$ coding region on the opposite strand from $c b b M$ and $c b b L$ ). Since the RegA-binding consensus features were based on only two bacterial species, it is possible that other RegA-binding sites occur upstream of $c b b M$ or $c b b L$ but could not be detected because they diverge from Rhodobacter motifs.
Transcriptional regulation of RubisCO genes is characteristically complex and is controlled by more than just the RegB/ RegA system. For example, there is undoubtedly also some positive control of form I and II RubisCO expression by the LysR-type transcriptional regulator CbbR (21). Both the form I and form II operons in T. denitrificans are adjacent to divergently transcribed $c b b R$ genes (5), and multiple putative CbbRbinding sites were found in upstream regions of both $c b b M$ and $c b b L$. To illustrate, in the intergenic region between $c b b L$ and the upstream $c b b R$ gene, there were putative, often overlapping CbbR-binding sites located from 4 to $17 \mathrm{nt}$ and 89 to 152 nt upstream from the translational start site. In the intergenic region between $c b b M$ and the upstream $c b b R$ gene, there were putative CbbR-binding sites located from 4 to $24 \mathrm{nt}$ and 64 to $127 \mathrm{nt}$ upstream from the translational start site. The motif used to identify putative CbbR-binding sites was $\mathrm{T}-\mathrm{N}_{12}-\mathrm{A}$, which deviates from the T- $\mathrm{N}_{11}$-A motif characteristic of LysRtype transcriptional regulators but may be more applicable to CbbR-binding sites in autotrophic bacteria (21). There is currently no evidence suggesting that $\mathrm{CbbR}$ influences differential expression of RubisCO genes under aerobic versus denitrifying conditions, and it is very possible that as-yet-unidentified transcriptional regulators may influence expression of RubisCO genes $(9,12)$.

Cytochrome $\boldsymbol{c} \boldsymbol{b} \boldsymbol{b}_{\mathbf{3}}$ oxidase. The gene cluster Tbd0643-0637, which includes genes putatively encoding one of two cytochrome $c b b_{3}$ oxidases in T. denitrificans (5), was upregulated under aerobic conditions (Table 2; Fig. 1). The first four genes in this cluster (Tbd0643-0640) appear to be $c c o N O Q P$, and the entire cluster is highly similar in terms of gene sequence and organization to a cluster in the related $\beta$-proteobacterium $A z o$ arcus sp. strain EbN1. Throughout this cluster in T. denitrificans, genes were upregulated 3.9- to 13.5 -fold relative to denitrifying conditions. The highest upregulation was for $c c o N$ (9.6fold) and $c \operatorname{co} Q$ (13.5-fold).

The results for $T$. denitrificans are generally consistent with those from $c c o N$ ::lac $Z$ transcriptional fusion studies of $R$. capsulatus and $R$. sphaeroides, which showed greater expression of $c c o N$ under aerobic, and particularly microaerophilic, conditions compared to anaerobic conditions $(24,29,30)$. Studies with $\operatorname{reg} A$ mutants of $R$. capsulatus suggest that RegA activates cytochrome $c b b_{3}$ oxidase expression semiaerobically or aerobically but represses expression anaerobically $(29,30)$. In contrast, FnrL apparently activates cytochrome $c b b_{3}$ oxidase expression semiaerobically or anaerobically in these two Rhodobacter species $(24,29)$.

The promoter region upstream of $c c o N$ was examined for potential RegA- and FNR-binding sites, as these transcription factors have been implicated in the regulation of cytochrome $c b b_{3}$ oxidases in Rhodobacter species. We focused on the promoter region of $c c o N$ because it is the first gene in this cluster and its upstream intergenic region is nearly $500 \mathrm{nt}$ long, whereas the intergenic regions upstream of $c c o O,-Q$, and $-P$ only range from 0 to $11 \mathrm{nt}$. A probable RegA-binding site (5'-GCGACACGTTGGCGC-3') was identified upstream of $\operatorname{ccoN}$; this putative binding site was located much closer to the translational start site (ca. $280 \mathrm{nt}$ upstream) than those we have identified in promoter regions of $c b b L$ and $c b b M$ (discussed previously). The most likely FNR-binding site identified in the ccoN promoter region was TTGAT...cTCgc, which was no- 

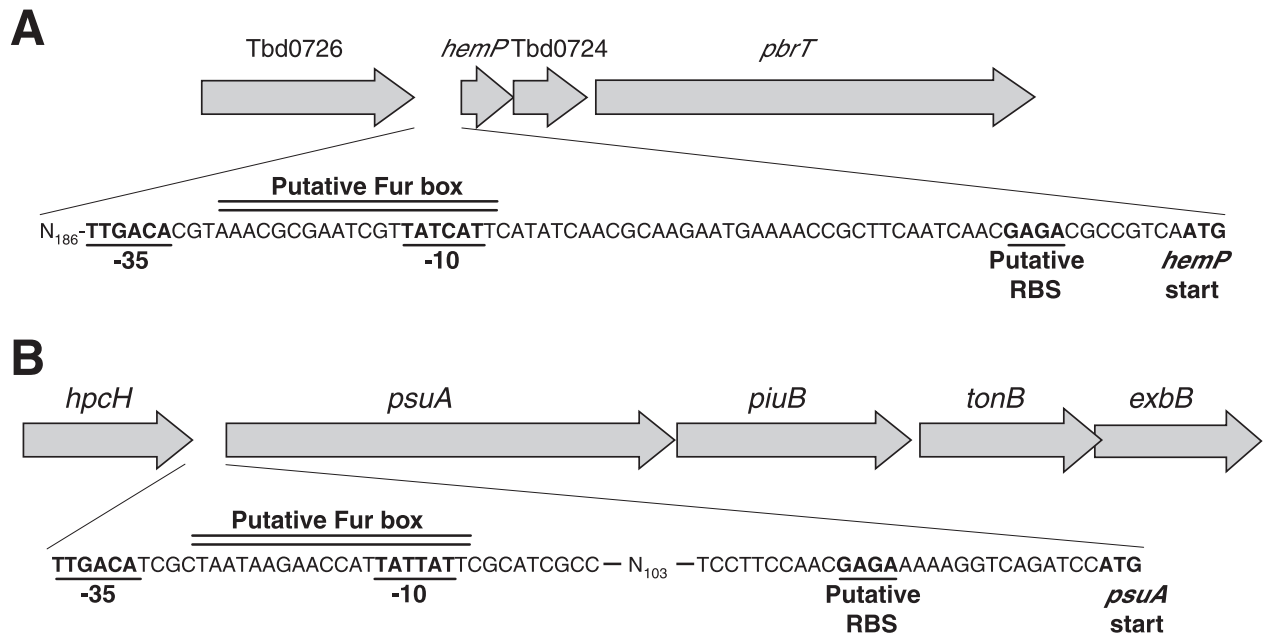

FIG. 4. Nucleotide sequences in the promoter regions of the hemP (A) and psuA (B) genes. The putative -35 and -10 promoter sequences as well as the putative Fur box sequences for both genes are indicated.

tably degenerate at the $3^{\prime}$ end and was located 374 nt upstream of the translational start site.

Chaperones and stress proteins. A number of genes associated with protein folding and turnover were upregulated under aerobic conditions (Table 2; Fig. 1). These include the genes encoding the molecular chaperones ClpB (Tbd0815; 9.6-fold upregulated), GroEL and GroES (Tbd0091-0092; 9.1- and 5.1fold upregulated, respectively), GrpE, DnaK, and DnaJ (Tbd1537-1539; 5.1- to 9.2-fold upregulated), and IbpA (Tbd1370; 6.3-fold upregulated). Several genes occurring in a cluster with GroEL and GroES were also aerobically upregulated, albeit to a lesser extent (Tbd0094-0096; 2.1- to 2.6-fold). Other aerobically upregulated genes encoding proteins that are putatively associated with protein folding and turnover include genes for HtpG (Tbd1078; 18-fold upregulated) and Lon protease (Tbd1252; 11-fold upregulated) (Table 2). Several of these genes have been found to be regulated in Escherichia coli by sigma 32 , the heat shock/stress alternative sigma factor (Tbd0345). Sigma 32-regulated genes include $c l p B$, grpE, $d n a J / d n a K, i b p A, h t p G$, and lon (35). In turn, several of the proteins encoded by these genes regulate intracellular levels of sigma 32, as do GroEL and GroES (13).

GroEL, an essential chaperone, and DnaK have been shown to play a significant role in the viability of E. coli (16). In E. coli, it has been demonstrated that about 250 proteins interact with GroEL, of which several could also utilize DnaK for proper folding (19). In the current study, both DnaK and GroEL were found to be significantly upregulated under aerobic conditions along with form I RubisCO, which has been shown to be a substrate of GroEL (17).

Iron acquisition. A cluster of 21 genes (Tbd0705 to Tbd0725), many of which are associated with $\mathrm{Fe}^{3+}$ uptake (5), includes the 16 most aerobically upregulated genes observed in this study (Table 2). In fact, all 21 genes in the cluster are among the top 50 aerobically upregulated genes (Table 2). The level of upregulation within the cluster varies widely, ranging from 6.1-fold upregulation for Tbd0707 to 159-fold upregulation for Tbd0725. Aerobic upregulation of iron transport genes in bacteria occurs in response to limited iron availability due to the lower solubility of $\mathrm{Fe}$ (III) species compared to $\mathrm{Fe}(\mathrm{II})$ species (1). To illustrate for the conditions used in this study, although the amounts of iron added to the aerobic and denitrifying cultures were similar (10 and $7.5 \mu \mathrm{M}$, respectively), equilibrium geochemical modeling (26) indicated that the amounts of dissolved iron under these two conditions differed dramatically. Whereas all of the $7.5 \mu \mathrm{M}$ iron would be present in solution under denitrifying conditions $\left(\sim 75 \%\right.$ as $\left.\mathrm{FeHCO}_{3}{ }^{+}\right)$, less than $0.7 \mu \mathrm{M}$ would be soluble under aerobic conditions [ $>93 \%$ of the $\mathrm{Fe}$ would be present as $\mathrm{Fe}(\mathrm{OH})_{3}$ precipitate].

Genes found in the cluster include those that encode proteins involved in siderophore biosynthesis and export (Tbd0716-0721), $\mathrm{Fe}^{3+}$-siderophore uptake across the outer membrane (Tbd0711-0713, Tbd0715, and Tbd0722), iron storage and mobility (Tbd0705), and heme uptake (Tbd0725). Systems involved in iron acquisition have been found to be regulated by the ferric uptake regulator protein, Fur (Tbd1123), which acts as a repressor in the presence of $\mathrm{Fe}^{2+}$ and a derepressor in the absence of $\mathrm{Fe}^{2+}$ (1). Putative DNA-binding sites allowing for Fur-dependent regulation $(1,34)$ were identified upstream of two genes in the cluster (Tbd0725 and Tbd0715) and overlapped with an E. coli-type sigma 70 promoter sequence for both genes (Fig. 4). The most highly upregulated gene, Tbd0725, encodes a putative homolog of HemP, a Furregulated protein associated with heme uptake in Yersinia en-

TABLE 3. E. coli-like sigma 70 consensus sequences identified in promoter regions of selected genes that were upregulated aerobically in T. denitrificans

\begin{tabular}{clcr}
\hline Tbd ORF & Gene & -35 sequence & -10 sequence \\
\hline 0705 & bfd & TTGACA & TAGAAT \\
0715 & psuA & TTGACA & TATTAT \\
0725 & hemP & TTGACA & TATCAT \\
0092 & groES & TTGAAA & TATTAT \\
1252 & lon & TTGAAA & GATACT \\
1538 & dnaK & TTGAAA & CATATT \\
0643 & ccoN & TTGACA & TATATT \\
1389 & nos $Z$ & TAGACA & TACATG \\
\hline
\end{tabular}




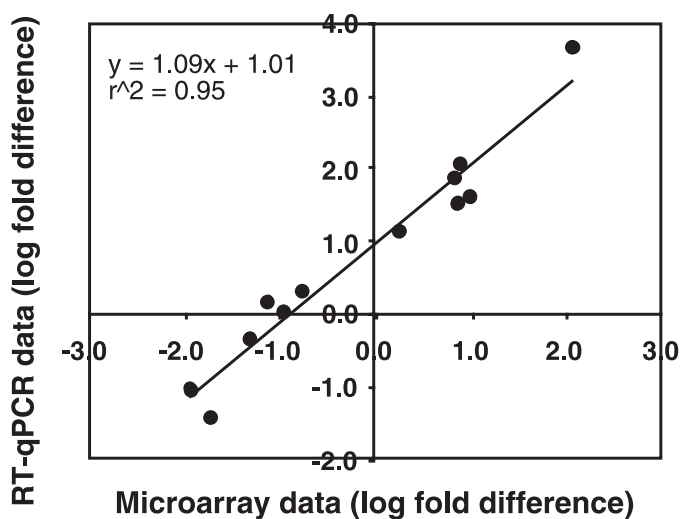

FIG. 5. Correlation between aerobic fold upregulation as determined by RT-qPCR versus microarray analysis for 12 genes: narG (Tbd1403), nirS (Tbd0077), norB (Tbd0561), nosZ (Tbd1389), $c b b S$ (Tbd2623), cbbL (Tbd2624), cbbM (Tbd2638), sqr (Tbd1407), $c c o N$ (Tbd0643), dsrC (Tbd1408), dsrC (Tbd1365), and $p v u A$ (Tbd0722).

terocolitica (28). Although other genes associated with heme uptake are not found in this gene cluster, they are found scattered throughout the $T$. denitrificans genome. The second gene, Tbd0715, encodes a homolog of PsuA, a Furregulated $\mathrm{Fe}^{3+}$-siderophore outer membrane receptor in Vibrio parahaemolyticus found associated with siderophore biosynthesis genes similar to those occurring in this $T$. denitrificans cluster (32).

Sequences closely matching the E. coli sigma 70 "consensus" sequences were also found in promoter regions of several other aerobically upregulated genes (Table 3), including bfd (Tbd0705), groES (Tbd0092), lon (Tbd1252), dnaK (Tbd1538), and ccoN (Tbd0643). As discussed previously, these genes encode proteins involved in a variety of functions, including iron uptake and storage, protein folding and turnover, and aerobic respiration via cytochrome $c b b_{3}$ oxidase. In contrast, promoter regions for anaerobically upregulated genes, including those involved in denitrification (narK, nirS, and norC) and carbon fixation $(c b b M)$, did not have sequences that closely matched the $E$. coli consensus sequence. Interestingly, the promoter region for $\operatorname{nos} Z$, which was slightly upregulated aerobically despite being associated with denitrification (Fig. 2), also contains sequences similar to the $E$. coli sigma 70 consensus sequences (Table 3).

RT-qPCR validation of microarray trends. Twelve genes were selected for analysis by RT-qPCR to confirm that differential expression indicated by the microarray data was supported by an independent method. The selected genes (listed in the legend for Fig. 5) cover a wide range of expression and include genes that were most upregulated under aerobic conditions and under denitrifying conditions. Overall, the RTqPCR data and microarray data were very consistent (Fig. 5); the data were highly correlated $\left(r^{2}=0.95\right)$ and had a slope that approached unity (1.085)

Concluding remarks. As one of the first whole-genome transcriptional studies of a chemolithotrophic bacterium, and one of the few studies addressing transcriptional analysis of genes associated with chemolithotrophic sulfur compound oxidation, this study provides a number of novel findings, including the following: (i) strong upregulation under denitrifying conditions of two copies of $s q r$ (which is explained by genomic location adjacent to the nar gene cluster for only one sqr copy), (ii) a variety of expression behaviors for the eight $d s r C$ copies (ranging from aerobic upregulation to anaerobic upregulation to constitutive expression at a high level), (iii) consistently highlevel expression under aerobic and denitrifying conditions of several important gene clusters associated with sulfur compound oxidation (including soxXYZA, dsrABEFHCMKLJOP, and the genes encoding ATP sulfurylase and APS reductase), (iv) differential expression of genes putatively encoding rhodanese (an enzyme function previously lacking direct evidence for its involvement in thiosulfate oxidation), and (v) differential expression of form I and II RubisCO under aerobic versus denitrifying conditions. Whereas this study provides some insight into the unusual ability of $T$. denitrificans to oxidize sulfur compounds under aerobic and denitrifying conditions, additional whole-genome transcriptional studies by our group will provide information on other unusual abilities of this bacterium, namely, catalysis of anaerobic, nitrate-dependent Fe(II) and U(IV) oxidation. Combining these microarray results with the use of a newly developed genetic system in T. denitrificans (T. Letain, S. Kane, T. Legler, H. Beller, E. Salazar, and P. Agron, unpublished data) will facilitate better understanding of the biochemical and genetic basis of the oxidative metabolism of this widespread but unusual bacterium.

\section{ACKNOWLEDGMENTS}

We thank NimbleGen Systems, Inc. and Feliza Bourguet (Lawrence Livermore National Laboratory) for their valuable experimental contributions, Donovan Kelly (University of Warwick, United Kingdom) for insightful comments on the manuscript, and Alex Beliaev (Pacific Northwest National Laboratory) for useful discussions about RNA handling.

This work was performed under the auspices of the U.S. Department of Energy by the University of California, Lawrence Livermore National Laboratory under contract no. W-7405-Eng-48.

\section{REFERENCES}

1. Andrews, S. C., A. K. Robinson, and F. Rodriguez-Quiñones. 2003. Bacterial iron homeostasis. FEMS Microbiol. Rev. 27:215-237.

2. Arai, H., M. Mizutani, and Y. Igarashi. 2003. Transcriptional regulation of the nos genes for nitrous oxide reductase in Pseudomonas aeruginosa. Microbiology (United Kingdom) 149:29-36.

3. Baumann, B., M. Snozzi, A. J. B. Zehnder, and J. R. van der Meer. 1996. Dynamics of denitrification activity of Paracoccus denitrificans in continuous culture during aerobic-anaerobic changes. J. Bacteriol. 178:4367-4374.

4. Beller, H. R. 2005. Anaerobic, nitrate-dependent oxidation of U(IV) oxide minerals by the chemolithoautotrophic bacterium Thiobacillus denitrificans. Appl. Environ. Microbiol. 71:2170-2174.

5. Beller, H. R., P. S. G. Chain, T. E. Letain, A. Chakicherla, F. W. Larimer, P. M. Richardson, M. A. Coleman, A. P. Wood, and D. P. Kelly. 2006. The genome sequence of the obligately chemolithoautotrophic, facultatively anaerobic bacterium Thiobacillus denitrificans. J. Bacteriol. 188:1473-1488.

6. Benjamini, Y., and Y. Hochberg. 1995. Controlling the false discovery rate: a practical and powerful approach to multiple testing. J. R. Stat. Soc. B 57:289-300.

7. Bolstad, B. M., R. A. Irizarry, M. Astrand, and T. P. Speed. 2003. A comparison of normalization methods for high density oligonucleotide array data based on variance and bias. Bioinformatics 19:185-193.

8. Cuypers, H., J. Berghöfer, and W. G. Zumft. 1995. Multiple nos Z promoters and anaerobic expression of nos genes necessary for Pseudomonas stutzeri nitrous oxide reductase and assembly of its copper centers. Biochim. Biophys. Acta 1264:183-190.

9. Dubbs, J. M., and F. R. Tabita. 2003. Interactions of the $\mathrm{cbb}_{\mathrm{II}}$ promoteroperator region with CbbR and RegA (PrrA) regulators indicate distinct mechanisms to control expression of the two cbb operons of Rhodobacter sphaeroides. J. Biol. Chem. 278:16443-16450.

10. Elsen, S., L. R. Swem, D. L. Swem, and C. E. Bauer. 2004. RegB/RegA, a 
highly conserved redox-responding global two-component regulatory system. Microbiol. Mol. Biol. Rev. 68:263-279.

11. English, R. S. C. A. Williams, S. C. Lorbach, and J. M. Shively. 1992. Two forms of ribulose 1,5-bisphosphate carboxylase/oxygenase from Thiobacillus denitrificans. FEMS Microbiol. Lett. 94:111-119.

12. Gibson, J. L., J. M. Dubbs, and F. R. Tabita. 2002. Differential expression of the $\mathrm{CO}_{2}$ fixation operons of Rhodobacter sphaeroides by the Prr/Reg twocomponent system during chemoautotrophic growth. J. Bacteriol. 184:66546664 .

13. Guisbert, E., C. Herman, C. Z. Lu, and C. A. Gross. 2004. A chaperone network controls the heat shock response in E. coli. Genes Dev. 18:28122821.

14. Hernandez, J. M., S. H. Baker, S. C. Lorbach, J. M. Shively, and F. R. Tabita. 1996. Deduced amino acid sequence, functional expression, and unique enzymatic properties of the form I and form II ribulose bisphosphate carboxylase/oxygenase from the chemoautotrophic bacterium Thiobacillus denitrificans. J. Bacteriol. 178:347-356.

15. Honisch, U., and W. G. Zumft. 2003. Operon structure and regulation of the nos gene region of Pseudomonas stutzeri, encoding an ABC-type ATPase for maturation of nitrous oxide reductase. J. Bacteriol. 185:1895-1902.

16. Horwich, A. L., K. B. Low, W. A. Fenton, I. N. Hirshfield, and K. Furtak. 1993. Folding in vivo of bacterial cytoplasmic proteins: role of GroEL. Cell 74:909-917.

17. Houry, W. A., D. Frishman, C. Eckerskorn, F. Lottspeich, and F. U. Hartl. 1999. Identification of in vivo substrates of the chaperonin GroEL. Nature 402:147-154.

18. Justin, P., and D. P. Kelly. 1978. Metabolic changes in Thiobacillus denitrificans accompanying the transition from aerobic to anaerobic growth in continuous chemostat culture. J. Gen. Microbiol. 107:131-137.

19. Kerner, M. J., D. J. Naylor, Y. Ishihama, T. Maier, H. C. Chang, A. P. Stines, C. Georgopoulos, D. Frishman, M. Hayer-Hartl, M. Mann, and F. U. Hartl. 2005. Proteome-wide analysis of chaperonin-dependent protein folding in Escherichia coli. Cell 122:209-220.

20. Körner, H., and W. G. Zumft. 1989. Expression of denitrification enzymes in response to the dissolved oxygen level and respiratory substrate in continuous culture of Pseudomonas stutzeri. Appl. Environ. Microbiol. 55:16701676.

21. Kusian, B., and B. Bowien. 1997. Organization and regulation of $c b b \mathrm{CO}_{2}$ assimilation genes in autotrophic bacteria. FEMS Microbiol. Rev. 21:135155.

22. Laguri, C., M. K. Phillips-Jones, and M. P. Williamson. 2003. Solution structure and DNA binding of the effector domain from the global regulato PrrA (RegA) from Rhodobacter sphaeroides: insights into DNA binding specificity. Nucleic Acids Res. 31:6778-6787.

23. Moir, J. W. B., D. J. Richardson, and S. J. Ferguson. 1995. The expression of redox proteins of denitrification in Thiosphaera pantotropha grown with oxygen, nitrate, and nitrous oxide as electron acceptors. Arch. Microbiol. 164:43-49.

24. Mouncey, N. J., and S. Kaplan. 1998. Oxygen regulation of the $c c o N$ gene encoding a component of the $c b b_{3}$ oxidase in Rhodobacter sphaeroides $2.4 .1^{\mathrm{T}}$ : involvement of the FnrL protein. J. Bacteriol. 180:2228-2231.

25. Paoli, G. C., and F. R. Tabita. 1998. Aerobic chemolithoautotrophic growth and RubisCO function in Rhodobacter capsulatus and a spontaneous gain of function mutant of Rhodobacter sphaeroides. Arch. Microbiol. 170:8-17.

26. Parkhurst, D. L., and C. A. J. Appelo. 1999. User's guide to PHREEQC (version 2): a computer program for speciation, batch-reaction, one-dimensional transport, and inverse geochemical calculations. U.S. Geol. Surv. Water-Res. Investig. Rep. 99-4259.

27. Schedel, M., and H. G. Trüper. 1979. Purification of Thiobacillus-denitrificans siroheme sulfite reductase and investigation of some molecular and catalytic properties. Biochim. Biophys. Acta 568:454-466.

28. Stojiljkovic, I., and K. Hantke. 1992. Hemin uptake system of Yersinia enterocolitica: similarities with other TonB-dependent systems in Gram-negative bacteria. EMBO J. 11:4359-4367.

29. Swem, D. L., and C. E. Bauer. 2002. Coordination of ubiquinol oxidase and cytochrome $\mathrm{cbb}_{3}$ oxidase expression by multiple regulators in Rhodobacter capsulatus. J. Bacteriol. 184:2815-2820.

30. Swem, L. R., S. Elsen, T. H. Bird, D. L. Swem, H.-G. Koch, H. Myllykallio, F. Daldal, and C. E. Bauer. 2001. The RegB/RegA two-component regulatory system controls synthesis of photosynthesis and respiratory electron transfer components in Rhodobacter capsulatus. J. Mol. Biol. 309:121-138.

31. Swem, L. R., B. J. Kraft, D. L. Swem, A. T. Setterdahl, S. Masuda, D. B. Knaff, J. M. Zaleski, and C. E. Bauer. 2003. Signal transduction by the global regulator RegB is mediated by a redox-active cysteine. EMBO J. 22:46994708.

32. Tanabe, T., T. Funahashi, H. Nakao, S. Miyoshi, S. Shinoda, and S. Yamamoto. 2003. Identification and characterization of genes required for biosynthesis and transport of the siderophore vibrioferrin in Vibrio parahaemolyticus. J. Bacteriol. 185:6938-6949.

33. Trüper, H. G. 1994. Reverse siroheme sulfite reductase from Thiobacillus denitrificans. Methods Enzymol. 243:422-426.

34. Wan, X., N. C. VerBerkmoes, L. A. McCue, D. Stanek, H. Connelly, L. J. Hauser, L. Wu, X. Liu, T. Yan, A. Leaphart, R. L. Hettich, J. Zhou, and D. K. Thompson. 2004. Transcriptomic and proteomic characterization of the Fur modulon in the metal-reducing bacterium Shewanella oneidensis. J. Bacteriol. 186:8385-8400.

35. Zhao, K., M. Liu, and R. R. Burgess. 2005. The global transcriptional response of Escherichia coli to induced $\sigma^{32}$ protein involves $\sigma^{32}$ regulon activation followed by inactivation and degradation of $\sigma^{32}$ in vivo. J. Biol. Chem. 280:17758-17768.

36. Zumft, W. G. 1997. Cell biology and molecular basis of denitrification Microbiol. Mol. Biol. Rev. 61:533-616. 


\section{UCRL-JRNL-226908}

LA WAE NCE LIWEAMCAE NATIONAL LABDAATOAY

Development of a Genetic System for the Chemolithoautotrophic Bacterium Thiobacillus denitrificans

T. E. Letain, S. R. Kane, T. C. Legler, E. P. Salazar, P. G. Agron, and H. R. Beller

Published May 2007

Published in Applied and Environmental Microbiology 


\title{
Development of a Genetic System for the Chemolithoautotrophic Bacterium Thiobacillus denitrificans ${ }^{\nabla}$
}

\author{
Tracy E. Letain, ${ }^{1}$ Staci R. Kane, ${ }^{1 *}$ Tina C. Legler, ${ }^{1}$ Edmund P. Salazar, ${ }^{1}$ \\ Peter G. Agron, ${ }^{2}$ and Harry R. Beller ${ }^{1}$ \\ Lawrence Livermore National Laboratory, Livermore, California $94551,{ }^{1}$ and Office of the President, \\ University of California, 300 Lakeside Drive, Sixth Floor, Oakland, California $94612^{2}$
}

Received 18 December 2006/Accepted 21 February 2007

\begin{abstract}
Thiobacillus denitrificans is a widespread, chemolithoautotrophic bacterium with an unusual and environmentally relevant metabolic repertoire, which includes its ability to couple denitrification to sulfur compound oxidation; to catalyze anaerobic, nitrate-dependent oxidation of $\mathrm{Fe}(\mathrm{II})$ and $\mathrm{U}(\mathrm{IV})$; and to oxidize mineral electron donors. Recent analysis of its genome sequence also revealed the presence of genes encoding two $[\mathrm{NiFe}]$ hydrogenases, whose role in metabolism is unclear, as the sequenced strain does not appear to be able to grow on hydrogen as a sole electron donor under denitrifying conditions. In this study, we report the development of a genetic system for $T$. denitrificans, with which insertion mutations can be introduced by homologous recombination and complemented in trans. The antibiotic sensitivity of $T$. denitrificans was characterized, and a procedure for transformation with foreign DNA by electroporation was established. Insertion mutations were generated by in vitro transposition, the mutated genes were amplified by the PCR, and the amplicons were introduced into $T$. denitrificans by electroporation. The IncP plasmid pRR10 was found to be a useful vector for complementation. The effectiveness of the genetic system was demonstrated with the hynL gene, which encodes the large subunit of a [NiFe]hydrogenase. Interruption of hynL in a hynL::kan mutant resulted in a $\mathbf{7 5 \%}$ decrease in specific hydrogenase activity relative to the wild type, whereas complementation of the hynL mutation resulted in activity that was $50 \%$ greater than that of the wild type. The availability of a genetic system in $T$. denitrificans will facilitate our understanding of the genetics and biochemistry underlying its unusual metabolism.
\end{abstract}

Thiobacillus denitrificans is a widespread, obligate chemolithoautotrophic bacterium with an unusual and environmentally relevant metabolic repertoire, which includes its ability to couple denitrification to sulfur compound oxidation; to catalyze anaerobic, nitrate-dependent oxidation of $\mathrm{Fe}(\mathrm{II})$ and $\mathrm{U}(\mathrm{IV})$; and to oxidize mineral electron donors such as FeS and $\mathrm{UO}_{2}$ (6 and references therein). More information about the metabolism of $T$. denitrificans emerged from recent analysis of its genome sequence, which revealed the presence of genes encoding two [NiFe]hydrogenases (6). Hydrogenases are metalloenzymes that catalyze the reversible oxidation of $\mathrm{H}_{2}$ to protons and are vital components of the energy metabolism of many microbes. Hydrogenases had not previously been reported in $T$. denitrificans even though this species was first isolated over a century ago (4). The role of these hydrogenases in $T$. denitrificans is unclear, as the sequenced strain does not appear to be able to grow on hydrogen as a sole electron donor under denitrifying conditions (6). Notably, hydrogen oxidation appears to be required for nitrate-dependent U(IV) oxidation by $T$. denitrificans (5), although the biochemical linkage between $\mathrm{H}_{2}$ and $\mathrm{U}(\mathrm{IV})$ oxidation has not been elucidated.

Based upon genome annotation, the two [NiFe]hydrogenases in $T$. denitrificans have been putatively characterized as follows (6): (i) a periplasmic group 1 [NiFe]hydrogenase (following the classification system described by Vignais et al. [22])

\footnotetext{
* Corresponding author. Mailing address: Lawrence Livermore National Laboratory, P.O. Box 808, L-542, Livermore, CA 94551-0808. Phone: (925) 422-7897. Fax: (925) 423-5764. E-mail: kane11@llnl.gov.

${ }^{\nabla}$ Published ahead of print on 2 March 2007.
}

presumed to catalyze $\mathrm{H}_{2}$ oxidation in vivo and (ii) a cytoplasmic, heterotetrameric, group $3 \mathrm{~b}$ [NiFe]hydrogenase (following the classification system described by Vignais et al. [22]) that is typically associated with $\mathrm{H}_{2}$ evolution as a means of disposing of excess reducing equivalents under fermentative conditions. A noteworthy feature of the group 1 hydrogenase is that it is encoded by an unusual gene cluster (hynS-isp1-isp2-hynL; Tbd_1378-1375) that has only been observed in four other microbes to date, none of which is a mesophilic, chemolithoautotrophic bacterium like $T$. denitrificans (6).

In this article, we describe the development of a genetic system in $T$. denitrificans that focuses on genetic disruption (and complementation in trans) of the group 1 hydrogenase. We chose to target a gene associated with the group 1 hydrogenase for several reasons: (i) presumably, this is the hydrogenase that catalyzes anaerobic $\mathrm{H}_{2}$ oxidation in $T$. denitrificans; (ii) accordingly, this is probably the hydrogenase that drives nitrate reduction during nitrate-dependent U(IV) oxidation (5); and (iii) the gene cluster encoding this hydrogenase is unusual, as noted previously. Specifically, we targeted the hynL gene, as this gene encodes the hydrogenase's large subunit, which harbors the active site (22). As described in this article, the somewhat unexpected results for the hydrogenase activity of the hynL knockout mutant led us to generate a double knockout containing mutations in the genes for the large subunits of both [NiFe]hydrogenases.

Relatively few genetic systems have been described for chemolithoautotrophic bacteria such as T. denitrificans. These include Halothiobacillus neapolitanus, which represents the earliest published example of the successful introduction of a 
TABLE 1 . Strains and plasmids used in this study

\begin{tabular}{|c|c|c|}
\hline Strain, plasmid, or transposon & Genotype or markers; characteristics and uses & Source or reference \\
\hline \multicolumn{3}{|l|}{ Strains } \\
\hline Escherichia coli TOP10 & $\begin{array}{l}\mathrm{F}^{-} \text {mcrA } \Delta(\text { mrr-hsdRMS-mcrBC }) \phi 80 l a c Z \Delta \mathrm{M} 15 \Delta \text { sacX74 recA1 araD139 } \\
\Delta(\text { ara-leu }) 7967 \text { galU galK rpsL }\left(\mathrm{Str}^{\mathrm{r}}\right) \text { endA1 nup } G\end{array}$ & Invitrogen \\
\hline \multicolumn{3}{|l|}{ Thiobacillus denitrificans } \\
\hline ATCC 25259 & Wild type & $\operatorname{ATCC}^{a}$ \\
\hline TL001 & hynL::kan & This work \\
\hline TL002 & hynL::kan hydA::gent & This work \\
\hline \multicolumn{3}{|l|}{ Plasmids } \\
\hline pUC19 & pMB1, Amp ${ }^{r}$; cloning vector & 24 \\
\hline pPA20 & pMB1, IncP Amp ${ }^{\mathrm{r}} \mathrm{Kan}^{\mathrm{r}}$; shuttle vector & 1 \\
\hline pANT4 & IncQ, $\mathrm{Amp}^{\mathrm{r}} \mathrm{Kan}^{\mathrm{r}} \mathrm{mob}^{+}$ & 15 \\
\hline pTnMod-OCm & pMB1, $\mathrm{Cam}^{\mathrm{r}} m o b^{+} \mathrm{Tn} 5 \mathrm{tnp}$ & 11 \\
\hline $\mathrm{pTn} M o d-O G m$ & pMB1, Gent ${ }^{\mathrm{r}} m o b^{+}$Tn5 tnp & 11 \\
\hline pTnMod-OKm' & pMB1, $\mathrm{Kan}^{\mathrm{r}} m o b^{+} \operatorname{Tn} 5 \operatorname{tnp}$ & 11 \\
\hline pTnMod-SmO & pMB1, $\mathrm{Spcm}^{\mathrm{r}} \operatorname{Str}^{\mathrm{r}} m o b^{+}$Tn5 tnp & 11 \\
\hline pTnMod-OTc & pMB1, Tet ${ }^{\mathrm{r}} m o b^{+}$Tn5 tnp & 11 \\
\hline pRR10 & IncP, $\mathrm{Amp}^{\mathrm{r}} m o b^{+} l a c Z \alpha$ & 19 \\
\hline pTL1 & IncP, Amp ${ }^{r}$, pRR10 with $\mathrm{P}_{\mathrm{Kan}}$ inserted at MCS & This work \\
\hline pTL2 & IncP, Gent ${ }^{\mathrm{r}}$ Amp $\mathrm{s}^{\mathrm{s}}$, pTL1 with bla::gent; $T$. denitrificans expression vector & This work \\
\hline pTL3 & $\begin{array}{l}\text { IncP, Gent }{ }^{\mathrm{r}} \text {, pTL2 with hynL-hupE inserted next to } \mathrm{P}_{\text {Kan }} \text { allowing for } \\
\text { expression }\end{array}$ & This work \\
\hline EZ-Tn5 pMOD-2<MCS $>$ & ColE1, Amp ${ }^{\mathrm{r}}$; transposon construction vector & EPICENTRE Biotechnologies \\
\hline pMOD- $2<$ gent $>$ & $\begin{array}{l}\text { ColE1, Amp }{ }^{\mathrm{r}} \text { Gent }^{\mathrm{r}} \text { with SacI fragment from } \mathrm{pTn} M o d-\mathrm{OGm} \text { containing } \\
\text { aacC1 inserted at MCS of pMOD-2 }\end{array}$ & This work \\
\hline pUC19-hynL & pMB1, Amp ${ }^{\mathrm{r}}$, pUC19 with hynL inserted at MCS & This work \\
\hline pUC19-hynL::kan & pMB1, Amp ${ }^{\mathrm{r}} \operatorname{Kan}^{\mathrm{r}}$, pUC19 with hynL::kan inserted at MCS & This work \\
\hline pUC19-hydA & pMB1, Amp ${ }^{\mathrm{r}}$, pUC19 with hydA inserted at MCS & This work \\
\hline pUC19-hydA::gent & pMB1, Amp ${ }^{\mathrm{r}}$ Gent $^{\mathrm{r}}$, pUC19 with hydA::gent inserted at MCS & This work \\
\hline \multicolumn{3}{|l|}{ Transposons } \\
\hline Tn-kan & $\begin{array}{l}\mathrm{Kan}^{\mathrm{r}}, \mathrm{EZ}-\mathrm{Tn} 5<\mathrm{KAN}-2>\text { DNA fragment with kanamycin resistance } \\
\text { selection marker located between Mosaic End Tn } 5 \text { transposase } \\
\text { recognition sequences }\end{array}$ & EPICENTRE Biotechnologies \\
\hline Tn-gent & $\begin{array}{l}\text { Gent }{ }^{\mathrm{r}}, \text { EZ-Tn5 pMOD- } 2<\text { gent }>\text { DNA fragment with gentamicin } \\
\text { resistance selection marker located between Mosaic End Tn } 5 \\
\text { transposase recognition sequences }\end{array}$ & This work \\
\hline
\end{tabular}

${ }^{a}$ ATCC, American Type Culture Collection, Manassas, VA.

wide-host-range plasmid into a chemolithoautotrophic bacterium $(3,14)$, and Acidithiobacillus ferrooxidans $(16,18)$, a bacterium widely used in mineral leaching and often associated with acid mine drainage. Other sulfur compound-metabolizing bacteria for which genetic systems have been described include the photolithoautotrophic bacterium Chlorobium tepidum (12) and the heterotrophic bacterium Geobacter sulfurreducens (9), both environmentally relevant organisms.

\section{MATERIALS AND METHODS}

Bacterial strains and plasmids. The plasmids and $T$. denitrificans (ATCC 25259) and Escherichia coli strains that were used in this study are described in Table 1.

Culturing conditions and growth media. E. coli was propagated according to established methods (20).

T. denitrificans cultures for electroporation and plasmid preparations were grown in modified M9 minimal medium (20) with additional constituents and vitamins prepared as described by Beller (5) and Widdel and Bak (23). The medium composition, per liter of water, was as follows: $6.8 \mathrm{~g}$ of $\mathrm{Na}_{2} \mathrm{HPO}_{4}, 3.0 \mathrm{~g}$ of $\mathrm{KH}_{2} \mathrm{PO}_{4}, 1.0 \mathrm{~g}$ of $\mathrm{NH}_{4} \mathrm{Cl}, 2.52 \mathrm{~g}$ of $\mathrm{NaHCO}_{3}, 4.96 \mathrm{~g}$ of $\mathrm{Na}_{2} \mathrm{~S}_{2} \mathrm{O}_{3} \cdot 5 \mathrm{H}_{2} \mathrm{O}, 2.02 \mathrm{~g}$ of $\mathrm{KNO}_{3}, 0.2 \mathrm{~g}$ of $\mathrm{MgSO}_{4} \cdot 7 \mathrm{H}_{2} \mathrm{O}, 0.03 \mathrm{~g}$ of $\mathrm{CaCl}_{2} \cdot 2 \mathrm{H}_{2} \mathrm{O}, 2.7 \mathrm{mg}$ of $\mathrm{FeCl}_{3} \cdot 6 \mathrm{H}_{2} \mathrm{O}, 0.18 \mathrm{mg}$ of $\mathrm{CuSO}_{4} \cdot 5 \mathrm{H}_{2} \mathrm{O}, 50 \mu \mathrm{g}$ of vitamin $\mathrm{B}_{12}, 100 \mu \mathrm{g}$ of thiamine, and $1 \mathrm{ml}$ of stock solution 6 (23). Solid medium also contained $15 \mathrm{~g}$ purified agar/liter (Oxoid, Hampshire, United Kingdom). Liquid cultures were grown on the bench top without aeration in capped flasks and tubes. Incubation of $T$. denitrificans on solid medium was per- formed inside an anaerobic glove box at $30^{\circ} \mathrm{C}$, as colony growth of $T$. denitrificans was found to be limited under aerobic conditions. Ultrapurified water (18-M $\Omega$ resistance) obtained from a Milli-Q UV Plus system (Millipore, Bedford, MA) was used to prepare the growth medium and all other aqueous solutions.

Antibiotics were used where appropriate in agar plates and liquid cultures at the following concentrations (unless indicated otherwise): ampicillin, 100 $\mu \mathrm{g} \mathrm{ml}^{-1}$; chloramphenicol, $50 \mu \mathrm{g} \mathrm{ml}^{-1}$; gentamicin, $50 \mu \mathrm{g} \mathrm{ml}^{-1}$; kanamycin, $50 \mu \mathrm{g} \mathrm{ml}^{-1}$; streptomycin, $50 \mu \mathrm{g} \mathrm{ml}^{-1}$; spectinomycin, $100 \mu \mathrm{g} \mathrm{ml}^{-1}$; tetracycline, $20 \mu \mathrm{g} \mathrm{ml}^{-1}$.

Determination of plating efficiency. The cell density of suspended T. denitrificans cultures was determined by measuring the absorbance at $600 \mathrm{~nm}$ of washed cell suspensions and was correlated with microscopic cell counts made with a Petroff-Hausser counting chamber (Hausser Scientific, Horsham, PA). The plating efficiency was determined by serially plating 10 -fold dilutions of the cell suspensions in triplicate and counting the CFU obtained.

DNA manipulations. Genomic DNA was isolated from $T$. denitrificans using a cetyltrimethylammonium bromide precipitation method (2). Plasmid DNA was isolated from E. coli and $T$. denitrificans using midi- or mini-plasmid purification kits (QIAGEN, Valencia, CA). PCR products and gel-excised plasmid fragments were purified with a QIAquick gel extraction kit (QIAGEN). Primers for amplification of $T$. denitrificans genomic DNA were designed from the whole genome sequence available through the Joint Genome Institute website at http: //genome.ornl.gov/microbial/tbden/ and in the GenBank/EMBL database under accession no. CP000116. PCR amplification of DNA fragments containing $T$. denitrificans sequence was typically performed using Advantage-GC 2 polymerase (Clontech, Mountain View, CA), except where noted, to improve yields for polymerization of the high-GC $(66 \%) T$. denitrificans DNA. Manufacturer's 
TABLE 2. Sequences of primers used in this study

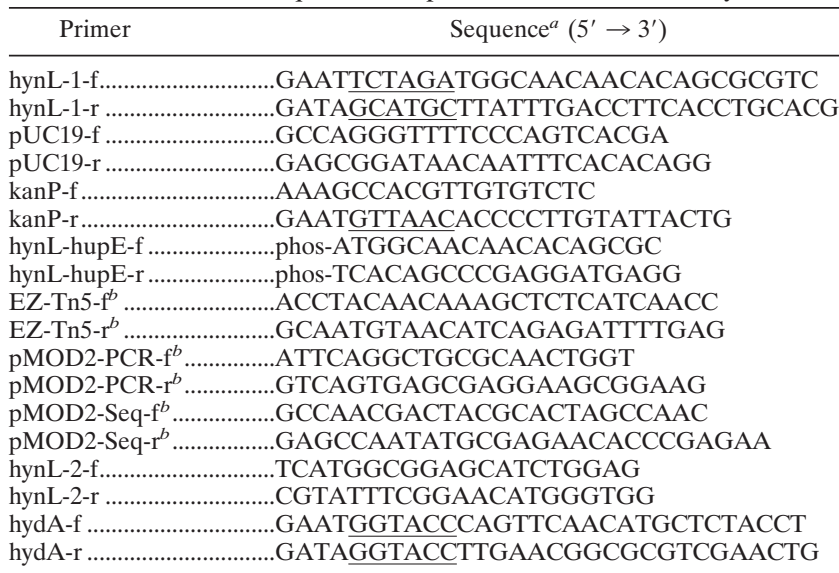

${ }^{a}$ phos denotes phosphorylated ends. Relevant restriction sites are underlined.

${ }^{b}$ EPICENTRE Biotechnologies, Madison, WI.

protocols were used when working with the EZ-Tn $5<\mathrm{KAN}-2>$ insertion kit and the EZ-Tn5 pMOD-2 $<$ MCS $>$ vector (EPICENTRE Biotechnologies, Madison, WI). DNA sequencing was performed by Davis Sequencing (Davis, CA).

Determination of antibiotic resistance. Various pTnMod minitransposon plas-

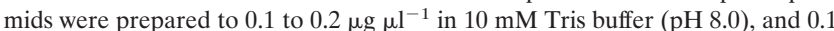
to $0.3 \mu \mathrm{g} \mu \mathrm{l}^{-1}$ was electroporated into $T$. denitrificans as described below. Recipient cells were plated on modified M9 solid medium containing one of the following: 20,25 , or $50 \mu \mathrm{g} \mathrm{ml}^{-1}$ kanamycin; 50 or $100 \mu \mathrm{g} \mathrm{ml}{ }^{-1}$ gentamicin; $50 \mu \mathrm{g}$ $\mathrm{ml}^{-1}$ streptomycin and $100 \mu \mathrm{g} \mathrm{ml}^{-1}$ spectinomycin; 5, 10, or $20 \mu \mathrm{g} \mathrm{ml}^{-1}$ tetracycline; or 20 or $25 \mu \mathrm{g} \mathrm{ml}^{-1}$ chloramphenicol.

Construction of hynL insertion mutant. In order to perform gene disruption via homologous recombination, a hynL::kan product was created. The hynL gene (Tbd_1375) was amplified from T. denitrificans genomic DNA using Vent DNA polymerase (New England BioLabs, Ipswich, MA) and hynL-1 primers containing an XbaI site in the forward primer and an SphI site in the reverse primer (Table 2). The resulting 1.8-kb PCR product was digested with XbaI and Sph and ligated into XbaI/SphI-digested pUC19. The resulting pUC19-hynL plasmid was subjected to in vitro transposition with an EZ-Tn $5<\mathrm{KAN}-2>$ cassette system (EPICENTRE Biotechnologies) and transformed into E. coli. Resulting kanamycin-resistant colonies were screened for Tn-kan (Table 1) placement within hynL and sequenced for the exact Tn-kan location using EZ-Tn5 primers (Table 2). Linear DNA containing hynL::kan for electroporation into $T$. denitrificans was generated from pUC19-hynL::kan with pUC19 primers (Table 2) and Hi-Fi Taq polymerase (Invitrogen, Carlsbad, CA).

Construction of complementation plasmid. A complementation plasmid (Fig. 1) was developed based on the IncP broad-host-range vector pRR10 (19). The kanamycin promoter, $\mathrm{P}_{\text {Kan }}(10)$, was amplified from $\mathrm{pTnMod}$-OKm' using kanP primers (Table 2) and Platinum Taq polymerase (Invitrogen). The resulting 110-bp amplicon was ligated into the SmaI site of pRR10, generating pTL1 (Table 1) and creating a unique HpaI site immediately downstream of $\mathrm{P}_{\mathrm{Kan}}$. In order to introduce gentamicin resistance into pTL1, a transposon containing the aminoglycoside acetyltransferase gene aacC1 was created. First, an 836-bp fragment containing aacC1 was cut from pTnMod-OGm (Table 1) with SacI. This same fragment was ligated into the SacI site of EZ-Tn5 pMOD-2<MCS $>$, creating pMOD- $2<$ gent $>$ (Table 1$)$. The gentamicin transposon Tn-gent (Table 1) was created according to the manufacturer's instructions via PCR amplification of pMOD-2<gent $>$ with pMOD2-PCR primers (Table 2) and transposed into pTL1, completing the complementation vector pTL2 (Table 1; Fig. 1). The transposition reaction products were electroporated into TOP10 E. coli cells. The resulting gentamicin-resistant colonies were screened for ampicillin sensitivity, and the exact location of $a a c C 1$ was confirmed by sequence analysis. To generate the final hynL expression vector, pTL3 (Table 1), a fragment containing hynL and the downstream gene hupE was amplified from T. denitrificans genomic DNA using hynL-hupE primers (Table 2) and Phusion DNA polymerase (Finnzymes, Espoo, Finland) and was ligated into the HpaI site of pTL2. The resulting clones were screened by PCR analysis for correct orientation of hynL-hupE relative to $\mathrm{P}_{\mathrm{Kan}}$, and the sequence was confirmed.

Construction of hydA insertion mutant. A disruption was created in the $T$. denitrificans gene encoding the large structural subunit of a group $3 \mathrm{~b}$ hydroge- nase, hydA (Tbd_1263), as follows. The hydA gene with approximately $1 \mathrm{~kb}$ flanking DNA on each end was amplified from $T$. denitrificans genomic DNA using KpnI-modified hydA primers (Table 2). The resulting 3.8-kb PCR product was digested with KpnI and ligated into KpnI-digested pUC19, yielding pUC19hydA (Table 1). This plasmid was subjected to in vitro transposition with Tn-gent and transformed into $E$. coli. Resulting gentamicin-resistant colonies were screened for Tn-gent placement within hydA and sequenced for the exact Tngent location using pMOD2-Seq primers (Table 2). Linear DNA containing hydA::gent for electroporation into $T$. denitrificans strain TL001 (Table 1) was generated from pUC19-hydA::gent with pUC19 primers (Table 2).

Electrocompetent cell preparation and electrotransformation. One Shot TOP10 Electrocomp E. coli cells (Table 1; Invitrogen) were purchased and transformed according to the manufacturer's instructions.

Electrocompetent $T$. denitrificans cells were prepared from 48-h (late log phase), 200-ml cultures (optical density at $600 \mathrm{~nm}=0.1$ to $0.25 ; 1 \times 10^{8}$ to $2.5 \times$ $10^{8}$ cells ml ${ }^{-1}$ ). All manipulations were carried out on ice, and all solutions were sterile and ice cold. Cells were harvested by centrifugation at $4^{\circ} \mathrm{C}$ for $10 \mathrm{~min}$ at $3,220 \times g$. The cells were washed twice in $100 \mathrm{ml}$ ultrapure $\mathrm{H}_{2} \mathrm{O}$ and resuspended in $500 \mu \mathrm{l}$ ultrapure $\mathrm{H}_{2} \mathrm{O}$. Cell integrity of $T$. denitrificans was monitored throughout the wash procedure by phase-contrast microscopy. Cells were freshly prepared immediately before electroporation.

All electrotransformations were performed in 0.2-cm-gap Bio-Rad Gene Pulser cuvettes using a Bio-Rad Gene Pulser II equipped with a Pulse Controller Plus. Electrocompetent $T$. denitrificans cells $(50 \mu \mathrm{l})$ were pulsed at $12.5 \mathrm{kV} \mathrm{cm}^{-1}$ for $\sim 5 \mathrm{~ms}$ (resistance $=200 \Omega$; capacitance $=25 \mu \mathrm{F}$ ). Typically, 2 to $5 \mu \mathrm{l}$ containing $\sim 100$ to $500 \mathrm{ng}$ DNA was used for electroporation. Cells were recovered in $1 \mathrm{ml}$ ice-cold, modified M9 medium immediately following electroporation and transferred into sterile $1.7-\mathrm{ml}$ Microfuge tubes. Electroporated cells were allowed to recover for $24 \mathrm{~h}$ at room temperature prior to plating on solid medium containing antibiotics. Each $T$. denitrificans electrotransformation experiment included a negative control in which no DNA was added. In all cases, no background growth of $T$. denitrificans on selective medium was observed.

Hydrogenase activity assay. In vivo assays were conducted with wild-type, mutant, and complemented mutant strains of $T$. denitrificans to assess specific hydrogenase activity. Cells (100 to $200 \mathrm{ml})$ were grown with thiosulfate and nitrate under strictly anaerobic conditions as described elsewhere (5), except that antibiotics were included in the growth medium (e.g., $50 \mu \mathrm{g} \mathrm{ml}{ }^{-1}$ kanamycin for the hynL mutant, $50 \mu \mathrm{g} \mathrm{ml}^{-1}$ gentamicin for the complemented mutant). Cultivation and handling of cells for the in vivo assay were conducted in an anaerobic glove box with headspace containing $\sim 3 \%$ hydrogen (5). T. denitrificans cells in

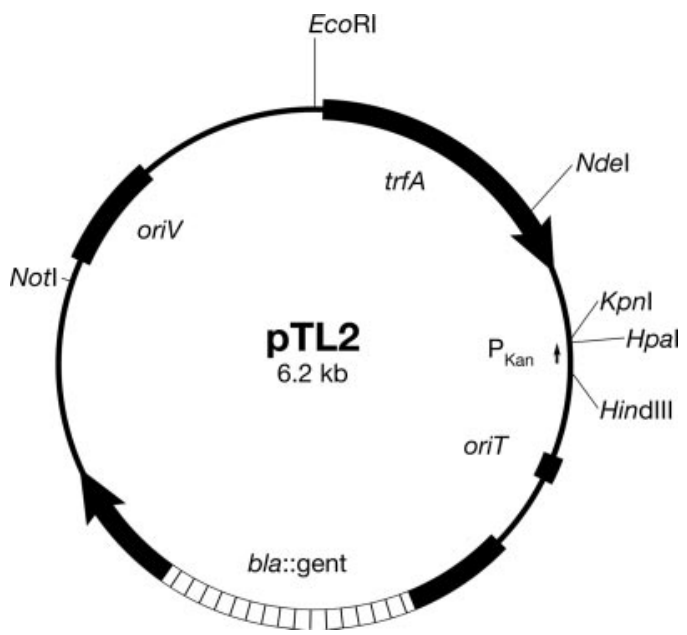

FIG. 1. Schematic diagram of the complementation vector (pTL2; Table 1) used in T. denitrificans. Plasmid construction is described in Materials and Methods. The following features are shown: oriV, the RK2 minimal vegetative origin of replication; oriT, the origin of transfer; $\operatorname{trf} A$, encodes the RK2 replication initiation protein; bla, the betalactamase gene encoding ampicillin resistance; $\mathrm{P}_{\mathrm{Kan}}$, the 110 -bp promoter of the kanamycin resistance gene from pTnMod-OKm'; and relevant restriction sites. The HpaI restriction site is unique and allows placement of genes for complementation. KpnI and HindIII bracket the original MCS from pRR10. 
late exponential phase $\left(\sim 2 \times 10^{8}\right.$ cells $\left.\mathrm{ml}^{-1}\right)$ were harvested anaerobically by centrifugation in sealed polycarbonate bottles and washed once with an anaerobic resuspension buffer described previously (5). Cells were then resuspended in

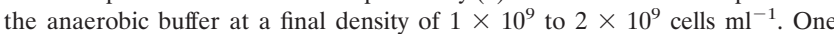
milliliter of this cell suspension was added to a quartz cuvette with a polytetrafluoroethylene stopper (1-cm path length; Spectrocell, Oreland, PA). Then, $10 \mu \mathrm{l}$ of an anaerobic $100 \mathrm{mM}$ benzyl viologen solution was added to the cuvette. The cuvette was then immediately sealed with the stopper, gently mixed, and quickly removed from the glove box for analysis. Reduction of benzyl viologen was monitored spectrophotometrically by measuring absorbance at $555 \mathrm{~nm}$ every $20 \mathrm{~s}$ for $5 \mathrm{~min}$. All materials used in the assays were stored in the anaerobic glove box for at least 1 day prior to use. Negative controls included assays without benzyl viologen or without hydrogen. The hydrogen-free negative controls involved a butyl rubber stopper rather than a polytetrafluoroethylene stopper and were prepared in the same manner as regular samples except that, after sealing the cuvette, the glove box atmosphere was replaced by alternately evacuating the cuvette headspace under vacuum and flushing with an $\mathrm{H}_{2}$-free, anaerobic mixture of $90 \% \mathrm{~N}_{2}-10 \% \mathrm{CO}_{2}$

\section{RESULTS AND DISCUSSION}

Growth on solid medium and characterization of antibiotic sensitivity. In order to allow the isolation of clonal populations of genetically modified $T$. denitrificans, plating onto solid growth medium was optimized. Medium solidified by the addition of purified agar (Oxoid) yielded the best results (see Materials and Methods), with visible colonies observed after 7 to 10 days of growth under anaerobic conditions at $30^{\circ} \mathrm{C}$. When late logarithmic liquid medium cultures containing $(1.3 \pm 0.2) \times$ $10^{8}$ cells $\mathrm{ml}^{-1}$ (mean \pm standard deviation; $n=16$ ) —as determined by direct cell counts in a Petroff-Hausser counting chamber-were plated on this medium, $(1.6 \pm 0.6) \times 10^{8} \mathrm{CFU}$ $\mathrm{ml}^{-1}(n=3)$ were recovered, demonstrating a high plating efficiency.

The growth of $T$. denitrificans on solid medium was inhibited by a variety of common antibiotics. Growth of $1 \times 10^{9}$ cells $\mathrm{ml}^{-1}$ plated on solid medium was inhibited by chloramphenicol $\left(50 \mu \mathrm{g} \mathrm{ml}^{-1}\right)$, gentamicin $\left(50 \mu \mathrm{g} \mathrm{ml}^{-1}\right)$, kanamycin $(50 \mu \mathrm{g}$ $\left.\mathrm{ml}^{-1}\right)$, streptomycin $\left(50 \mu \mathrm{g} \mathrm{ml}^{-1}\right)$ plus spectinomycin $(100 \mu \mathrm{g}$ $\left.\mathrm{ml}^{-1}\right)$, and tetracycline $\left(5 \mu \mathrm{g} \mathrm{ml}^{-1}\right)$. The growth of $T$. denitrificans in liquid medium was similarly inhibited, with one difference: T. denitrificans grown in liquid medium also displayed sensitivity to ampicillin $\left(100 \mu \mathrm{g} \mathrm{ml}^{-1}\right)$. As T. denitrificans takes much longer to grow on solid medium (10 days, as opposed to 2 days in liquid medium), it is likely that the ampicillin had degraded during the 10 days it took for growth to occur on solid medium. These results indicated that several different antibiotic resistance markers could be used for selection of genetic variants.

Identification of potential expression vectors. Both broadand narrow-host-range plasmids (13) were tested for the ability to replicate within $T$. denitrificans. The plasmids were introduced by electroporation, and viability after electroporation was demonstrated by both $\mathrm{N}_{2}$ bubble formation (evidence of denitrification) and growth on solid media.

An IncP plasmid containing the RK2 minireplicon, pPA20 (1), and an IncQ plasmid, pANT4 (15), were evaluated for the ability to replicate in T. denitrificans. Electroporation of pPA20 into $T$. denitrificans resulted in multiple kanamycin-resistant isolates ( 5 to 10 isolates $\mu g^{-1}$ DNA). To ensure that pPA20 was successfully replicating in $T$. denitrificans, the plasmid was purified from one of the kanamycin-resistant transformants, checked for correct size by gel electrophoresis (data not shown), and reintroduced into T. denitrificans via electroporation. A significant increase in the number of transformants $\mu \mathrm{g}^{-1}$ of plasmid DNA was seen with pPA20 isolated from $T$. denitrificans $\left(1.4 \times 10^{6}\right.$ transformants $\left.\mu \mathrm{g}^{-1}\right)$ when compared to pPA20 isolated from $E$. coli (5 to 10 transformants $\mu \mathrm{g}^{-1}$ ), a $10^{5}$-fold increase. The low number of transformants resulting from the E. coli-purified plasmid is likely a result of plasmid degradation by host restriction/modification systems, of which T. denitrificans has several (6). Electroporation of pANT4 into $T$. denitrificans yielded no kanamycin-resistant isolates after several attempts.

Analysis of antibiotic resistance determinants in $\boldsymbol{T}$. denitrificans. A series of minitransposon vectors (Table 1) were used to confer functional antibiotic resistance in $T$. denitrificans, including pTnMod-OKm' $\left(\operatorname{Kan}^{\mathrm{r}}\right)$, pTnMod-SmO $\left(\operatorname{Str}^{\mathrm{r}} \operatorname{Spcm}^{\mathrm{r}}\right)$, pTnMod-OGm $\left(\right.$ Gent $\left.^{r}\right)$, pTnMod-OCm $\left(\mathrm{Cam}^{\mathrm{r}}\right)$, and pTnModOTc $\left(\operatorname{Tet}^{\mathrm{r}}\right)$, containing Tn5 inverted repeats, the transposase external to the repeats, and a conditional origin of replication (11). Evaluation of these five different antibiotic resistance determinants contained on $\mathrm{pTn}$ Mod vectors showed that three constructs resulted in functional antibiotic resistance after transposition into the $T$. denitrificans genome, including kanamycin, gentamicin, and streptomycin-spectinomycin resistance. Electroporation of $T$. denitrificans with pTnMod-OTc and pTnMod-OCm did not result in tetracycline- or chloramphenicol-resistant colonies, respectively, using 5, 10, and $20 \mu \mathrm{g}$ tetracycline $\mathrm{ml}^{-1}$ or 25 and $50 \mu \mathrm{g}$ chloramphenicol $\mathrm{ml}^{-1}$. Since no colonies were obtained, it is not clear whether the lack of resistance resulted from lack of gene expression or lack of functionality of the antibiotic resistance marker in $T$. denitrificans.

Development of a gene disruption system for hynL and hydA. In order to disrupt the genes encoding the hydrogenase large structural subunits within $T$. denitrificans, gene replacement of hyn $L$ by hynL::kan, and of hydA by hydA::gent, was performed by using homologous recombination. Electroporation of wildtype $T$. denitrificans with $250 \mathrm{ng}$ of hynL::kan linear DNA resulted in $10 \mathrm{CFU}$ on modified $\mathrm{M} 9 \mathrm{Km}_{50}$ plates after 7 to 10 days. PCR analysis with hynL-2 primers (Table 2), which anneal outside of the hynL gene (Fig. 2), was used to confirm homologous recombination within the $T$. denitrificans genome. Production of the expected 3.1-kb band (Fig. 2, lane 3) signified that hynL::kan recombined properly within the genome. Sequence analysis of the PCR products confirmed that the Tn-kan insertion was located 801 bases downstream from the hynL translation start site in the T. denitrificans genome. PCR analysis of pUC19-hynL::kan (Table 1; the plasmid used to generate the linear DNA fragment used for electroporation) with hynL-2 primers generated no product, as expected (data not shown).

The confirmed hynL knockout strain (TL001; Table 1) was used to generate a second knockout in a group $3 \mathrm{~b}$ hydrogenase, hydA. Homologous recombination of wildtype hydA with hydA::gent was successful, resulting in 60 to 75 colonies $\mu \mathrm{g}^{-1}$ of transformed linear DNA. One strain, TL002 (Table 1), showed the correct-size product for hyd $A$ ::gent amplification (data not shown) and was also confirmed by sequence analysis, which showed that the disruption was located $182 \mathrm{bp}$ from the translation start site. 


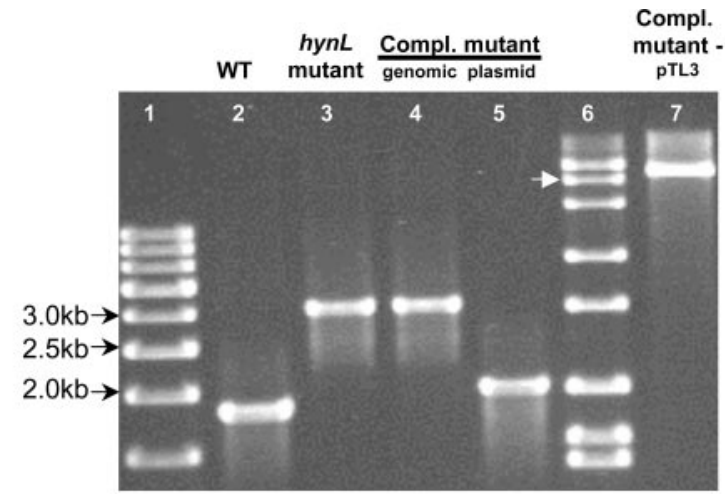

B

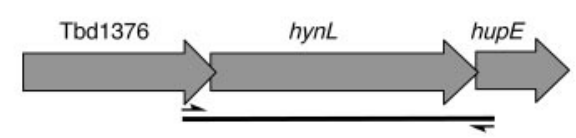

$1.9 \mathrm{~kb}$

Lane 2

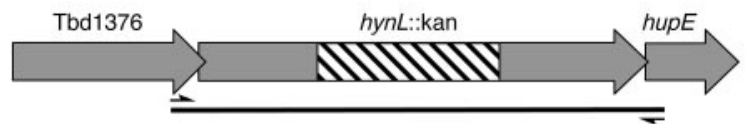

$3.1 \mathrm{~kb}$

Lane 5

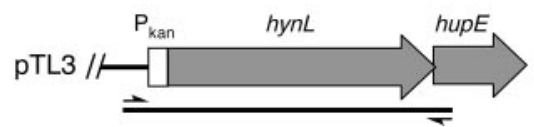

$2.0 \mathrm{~kb}$

FIG. 2. (A) Electropherogram of PCR products from wild-type (WT) T. denitrificans, the hynL mutant, and the complemented (Compl.) hynL mutant, as well as digested plasmid DNA from the complemented mutant. Lane 1, HyperLadder III, Bioline; lane 2, wild-type DNA, primers hynL-2-f and -r; lane 3, hynL mutant (strain TL001) DNA, primers hynL-2-f and -r; lane 4, complemented-mutant genomic DNA, primers hynL-2-f and -r; lane 5, complemented-mutant plasmid DNA, primers hynL-2-r and pUC19-r; lane 6, Hi-Lo Marker, Bionexus (the arrow indicates $8 \mathrm{~kb}$ ); lane 7, complemented-mutant pTL3 plasmid DNA, NdeI digested. (B) Maps of primer positions and amplicon sizes corresponding to lanes 2 to 5 in panel A. Note that the hynL-2-f primer anneals with genomic DNA upstream of the hynL gene, whereas the pUC19-r primer anneals with pTL3 plasmid DNA, rendering these primers specific to the $T$. denitrificans genome and the complementation plasmid pTL3, respectively.

For both strains TL001 and TL002, no growth defects were apparent during cultivation with thiosulfate and nitrate.

Development of a complementation system to allow for intrans expression of the hynL gene. To demonstrate that the phenotype of the mutant strain TL001 was due to disruption of the hydrogenase large structural subunit (hynL), and not due to a secondary gene mutation, an expression vector containing hynL was constructed. While pPA20 was able to replicate in $T$. denitrificans, it is not ideally suited as an expression vector due to its relatively large size $(8 \mathrm{~kb})$ and lack of a multiple cloning site (MCS). Since the RK2 minireplicon of plasmid pPA20 was sufficient for replication in T. denitrificans, other plasmids containing the same replicon were considered. The broad-hostrange plasmid pRR10 (19) was used as the basis for the complementation vector since it contains the same replicon as pPA20, is relatively small, and contains the pUC19 MCS and $l a c Z_{\alpha}$ fragment (for insert screening). As ampicillin resistance is not an effective selectable marker for $T$. denitrificans on solid medium, a gentamicin-resistant variant of pRR10 was generated. The aacC1 gene from pTnMod-OGm served as the gentamicin resistance marker in pRR10; after transposition, Tn-gent (containing aacC1) (Table 1) was determined by sequence analysis to be located $400 \mathrm{bp}$ into the bla gene (Fig. 1).
The gene cluster containing the group 1 hydrogenase gene disruption has five genes between hynL and the promoter, with one additional gene, hupE, located immediately downstream of hynL (6). Microarray expression data (7 and unpublished data), as well as the short intergenic gaps between genes in this cluster, are consistent with the transcription of both hynL and hupE being dependent on a promoter located at the beginning of this cluster, approximately $4 \mathrm{~kb}$ upstream of hynL. Since identification of the hynL promoter was uncertain, an alternate promoter from the $\operatorname{aph}\left(3^{\prime}\right)-I$ gene encoding kanamycin resistance on pTnMod-OKm' was used instead of the native hynL promoter.

Approximately $100 \mathrm{ng}$ of the complementation vector pTL3 was electroporated into TL001, and two to five gentamicinresistant isolates were obtained. An $8.6-\mathrm{kb}$ plasmid purified from a gentamicin-resistant TL001 isolate (Fig. 2, lane 7) was confirmed to contain hynL-hupE by both PCR analysis (Fig. 2, lane 5) and sequence analysis of the recovered plasmid. In addition, hynL-2 primers were used to confirm the maintained presence of hynL::kan within complemented strain TL001 (Fig. 2, lane 4).

Effect of genetic manipulations on hydrogenase activity. Interruption of the hynL gene, which encodes the large, activesite-bearing subunit of a periplasmic [NiFe]hydrogenase (6), 


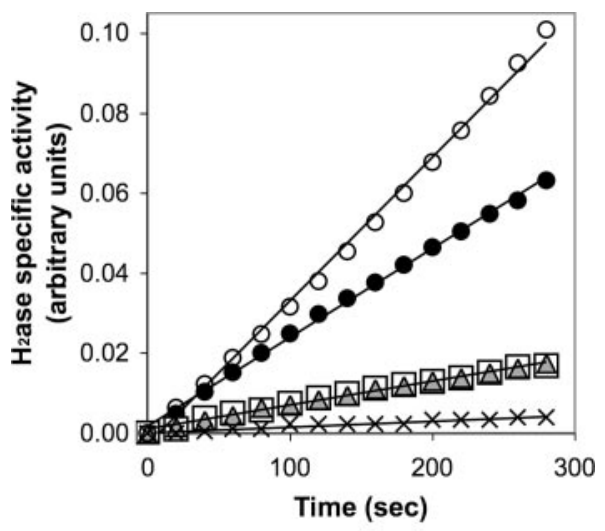

\begin{tabular}{|cl|}
\hline O & Complemented hynL mutant \\
$\square$ & Wild type \\
$\square$ & hynL mutant \\
$\Delta$ & Double mutant \\
$\mathrm{X}$ & Negative controls \\
\hline
\end{tabular}

FIG. 3. Hydrogen oxidation (measured as in vivo benzyl viologen reduction) versus time for wild-type $T$. denitrificans, strain TL001 (hynL mutant), strain TL002 (hynL hydA double mutant), and the complemented hynL mutant (TL001/pTL3). Negative controls (averaged results for controls with no $\mathrm{H}_{2}$ and controls with no benzyl viologen) are also shown. Each datum point represents the average of duplicate or triplicate assays. Linear-regression fits are plotted.

resulted in a dramatic decrease in specific hydrogenase activity (Fig. 3). Compared to the rate of specific hydrogen oxidation in wild-type cells, the rate in mutant strain TL001 was, on average, $75 \%$ reduced in replicate experiments. The hydrogenase assay proved to be generally robust, as specific rates in replicate experiments with wild-type cells agreed within $1 \%$. Negative control assays that excluded hydrogen or benzyl viologen resulted in rates that were negligible relative to the wild type (Fig. 3). Complementation of the hynL mutation (strain TL001/pTL3; Table 1) resulted in specific hydrogenase activity that exceeded that of the wild type (Fig. 3). Overall, the assay results for the hynL::kan mutant (strain TL001) and the complemented mutant indicate that the genetic system described here enabled successful manipulation of a targeted gene in $T$. denitrificans.

The observation that interruption of the hynL gene did not completely eliminate hydrogenase activity merits further discussion. Contamination with a wild-type copy of hynL is largely ruled out because we grew the TL001 culture in medium containing $50 \mu \mathrm{g} \mathrm{ml}^{-1}$ kanamycin and could not detect the wildtype hynL gene in PCR analyses (including more sensitive real-time PCR analyses [data not shown]) of TL001 cultures that were subjected to the hydrogenase assay (Fig. 2, lane 3). We first hypothesized that the other hydrogenase in T. denitrificans, putatively a cytoplasmic, group $3 \mathrm{~b}$ [NiFe]hydrogenase (6), was responsible for this residual activity in strain TL001. This would have been a noteworthy phenomenon, as homologous group $3 \mathrm{~b}$ hydrogenases (e.g., in the well-studied hyperthermophile Pyrococcus furiosus) are characteristically $\mathrm{H}_{2}-$ evolving enzymes involved in disposing of excess reductant under fermentative conditions (22) rather than $\mathrm{H}_{2}$-oxidizing enzymes that would function under the denitrifying conditions of this study. However, hydrogenase assays conducted with a double mutant (TL002; with mutations in the large subunits of both [NiFe]hydrogenases) indicated very similar activity to that of the single hynL mutant (Fig. 3), suggesting that the group $3 b$ hydrogenase was not catalyzing significant hydrogen oxidation activity. The residual hydrogenase activity in the double mutant leaves open the possibility that an additional hydrogenase is encoded in the T. denitrificans genome but has not yet been identified. However, BLASTP searches for other kinds of hydrogenases (e.g., [Fe]hydrogenases, $\mathrm{H}_{2}$-forming methylenetetrahydromethanopterin dehydrogenase, E. coli hydrogenase 3 ) against the $T$. denitrificans genome did not reveal convincing evidence of additional hydrogenases.

An alternative explanation for residual hydrogenase activity in the hynL mutant is that the translated product of the disrupted gene was still capable of catalyzing hydrogen oxidation, albeit at a greatly reduced level. This seems unlikely for two reasons: (i) the EZ-Tn5 $<\mathrm{KAN}-2>$ cassette contains stop codons in all three reading frames, which should preclude expression of a large portion (more than half) of the hynL gene, and (ii) the assembly and maturation of the active site of the hydrogenase should not proceed properly in the absence of key features at the C-terminal end of HynL, including the two cysteine residues in the very highly conserved C-terminal motif DPCxxCxxH/R and the endolytically formed peptide with a cleavage site located immediately downstream of this motif (8). The two conserved cysteine residues in this motif (along with two conserved cysteine residues in the N-terminal region of HynL) ligate the metal center to the large subunit (17).

The physiological role of hydrogenases in $T$. denitrificans remains unclear. Although the bacterium can oxidize $\mathrm{H}_{2}$ as a sole electron donor under denitrifying conditions, this metabolism does not support growth (6) and appears to be relatively slow. Under the assay conditions used in this study (i.e., cells grown under denitrifying conditions with thiosulfate in the presence of $\mathrm{H}_{2}$ and then resuspended with $\mathrm{H}_{2}$ as the sole electron donor), in vivo, specific activity was on the order of 3 $\mathrm{nmol} \cdot \min ^{-1} \cdot \mathrm{mg}$ protein ${ }^{-1}$ (based on a molar absorption coefficient for benzyl viologen of $7,780 \mathrm{M}^{-1} \cdot \mathrm{cm}^{-1}$ ) (21). The use of hydrogenases in an $\mathrm{H}_{2}$-evolving mode to dispose of excess reducing equivalents under fermentative conditions cannot be reconciled with the obligate chemolithotrophic lifestyle of T. denitrificans, which has never been shown to function under fermentative conditions. Now that a genetic system is available for $T$. denitrificans, mutants defective in each of the two encoded hydrogenases can be compared under a range of physiological conditions, which should enhance our understanding of the roles of each hydrogenase. In addition, traditional biochemical studies can be conducted with the double mutant (strain TL002) to investigate the possibility that there is a third, as-yet-unidentified hydrogenase in T. denitrificans.

\section{ACKNOWLEDGMENTS}

We thank Thomas Hanson (University of Delaware) for valuable technical discussions.

This work was performed under the auspices of the U.S. Department of Energy by the University of California, Lawrence Livermore National Laboratory, under contract W-7405-Eng-48. 


\section{REFERENCES}

1. Agron, P. G., P. Sobecky, and G. L. Andersen. 2002. Establishment of uncharacterized plasmids in Escherichia coli by in vitro transposition. FEMS Microbiol. Lett. 217:249-254.

2. Ausubel, F. M., R. Brent, R. E. Kingston, D. D. Moore, J. G. Seidman, J. A Smith, and K. Stuhl. 1987. Current protocols in molecular biology. John Wiley \& Sons, Inc., New York, NY.

3. Baker, S. H., S. Jin, H. C. Aldrich, G. T. Howard, and J. M. Shively. 1998 Insertion mutation of the form I $c b b L$ gene encoding ribulose bisphosphate carboxylase/oxygenase (RuBisCO) in Thiobacillus neapolitanus results in expression of form II RuBisCO, loss of carboxysomes, and an increased $\mathrm{CO}_{2}$ requirement for growth. J. Bacteriol. 180:4133-4139.

4. Beijerinck, M. W. 1904. Phénomènes de réduction produits par les microbes (Conférence avec demonstrations faite-Delft, le 16 avril 1903). Arch. Neerl Sci. Ser. 2 9:131-157.

5. Beller, H. R. 2005. Anaerobic, nitrate-dependent oxidation of U(IV) oxide minerals by the chemolithoautotrophic bacterium Thiobacillus denitrificans Appl. Environ. Microbiol. 71:2170-2174.

6. Beller, H. R., P. S. G. Chain, T. E. Letain, A. Chakicherla, F. W. Larimer, P. M. Richardson, M. A. Coleman, A. P. Wood, and D. P. Kelly. 2006. The genome sequence of the obligately chemolithoautotrophic, facultatively anaerobic bacterium Thiobacillus denitrificans. J. Bacteriol. 188:1473-1488.

7. Beller, H. R., T. E. Letain, A. Chakicherla, S. R. Kane, T. C. Legler, and M. A. Coleman. 2006. Whole-genome transcriptional analysis of chemolithoautotrophic thiosulfate oxidation by Thiobacillus denitrificans under aerobic versus denitrifying conditions. J. Bacteriol. 188:7005-7015

8. Böck, A., P. W. King, M. Blokesch, and M. C. Posewitz. 2006. Maturation of hydrogenases. Adv. Microb. Physiol. 51:1-71.

9. Coppi, M. V., C. Leang, S. J. Sandler, and D. R. Lovley. 2001. Development of a genetic system for Geobacter sulfurreducens. Appl. Environ. Microbiol. 67:3180-3187.

10. de Lorenzo, V., M. Herrero, U. Jakubzik, and K. N. Timmis. 1990. Mini-Tn transposon derivatives for insertion mutagenesis, promoter probing, an chromosomal insertion of cloned DNA in gram-negative eubacteria. J. Bacteriol. 172:6568-6572.

11. Dennis, J. J., and G. J. Zylstra. 1998. Plasposons: modular self-cloning mini-transposon derivatives for the rapid genetic analysis of gram-negative bacterial genomes. Appl. Environ. Microbiol. 64:2710-2715.

12. Hanson, T. E., and F. R. Tabita. 2001. A ribulose-1,5-bisphosphate carboxylase/oxygenase ( $\mathrm{RuBisCO})$-like protein from Chlorobium tepidum that is involved with sulfur metabolism and the response to oxidative stress. Proc. Natl. Acad. Sci. USA 98:4397-4402.

13. Kües, U., and U. Stahl. 1989. Replication of plasmids in gram-negative bacteria. Microbiol. Rev. 53:491-516.

14. Kulpa, C. F., M. T. Roskey, and M. T. Travis. 1983. Transfer of plasmid RP1 into chemolithotrophic Thiobacillus neapolitanus. J. Bacteriol. 156:434-436.

15. Lee, A. K., and S. Falkow. 1998. Constitutive and inducible green fluorescent protein expression in Bartonella henselae. Infect. Immun. 66:3964-3967.

16. Liu, Z., N. Guiliani, C. Appia-Ayme, F. Borne, J. Ratouchniak, and V. Bonnefoy. 2000. Construction and characterization of a recA mutant of Thiobacillus ferrooxidans by marker exchange mutagenesis. J. Bacteriol. 182: 2269-2276.

17. Magalon, A., and A. Böck. 2000. Analysis of the HypC-HycE complex, a key intermediate in the assembly of the metal center of the Escherichia coli hydrogenase 3. J. Biol. Chem. 275:21114-21120.

18. Peng, J. B., W. M. Yan, and X. Z. Bao. 1994. Plasmid and transposon transfer to Thiobacillus ferrooxidans. J. Bacteriol. 176:2892-2897.

19. Roberts, R. C., R. Burioni, and D. R. Helinski. 1990. Genetic characterization of the stabilizing functions of a region of broad-host-range plasmid RK2. J. Bacteriol. 172:6204-6216.

20. Sambrook, J., and D. W. Russell. 2001. Molecular cloning: a laboratory manual, 3rd ed. Cold Spring Harbor Laboratory Press, Cold Spring Harbor, NY.

21. Spencer, M. E., and J. R. Guest. 1973. Isolation and properties of fumarate reductase mutants of Escherichia coli. J. Bacteriol. 114:563-570.

22. Vignais, P. M., B. Billoud, and J. Meyer. 2001. Classification and phylogeny of hydrogenases. FEMS Microbiol. Rev. 25:455-501.

23. Widdel, F., and F. Bak. 1992. Gram-negative mesophilic sulfate-reducing bacteria, p. 3352-3378. In A. Balows, H. G. Trüper, M. Dworkin, W. Harder, and K.-H. Schleifer (ed.), The prokaryotes. Springer Verlag, New York, NY.

24. Yanisch-Perron, C., J. Vieira, and J. Messing. 1985. Improved M13 phage cloning vectors and host strains: nucleotide sequences of the M13mp18 and pUC19 vectors. Gene 33:103-119. 